\title{
Towards a more detailed representation of high-latitude vegetation in the global land surface model ORCHIDEE (ORC-HL-VEGv1.0)
}

\author{
Arsène Druel $^{1,2}$, Philippe Peylin ${ }^{1}$, Gerhard Krinner ${ }^{2}$, Philippe Ciais ${ }^{1}$, Nicolas Viovy ${ }^{1}$, Anna Peregon ${ }^{1,3}$, \\ Vladislav Bastrikov ${ }^{1}$, Natalya Kosykh ${ }^{3}$, and Nina Mironycheva-Tokareva ${ }^{3}$ \\ ${ }^{1}$ Laboratoire des Sciences du Climat et de l'Environnement, CEA-CNRS-UVSQ CE Orme des Merisiers, \\ 91190 Gif sur Yvette, France \\ ${ }^{2}$ CNRS, Univ. Grenoble Alpes, Institut des Géosciences de l'Environnement (IGE), 38000 Grenoble, France \\ ${ }^{3}$ Institute of Soil Science and Agrochemistry, Siberian Branch Russian Academy of Sciences (SB RAS), \\ Novosibirsk, 630090, Ak. Lavrentieva ave., 8/2, Russia
}

Correspondence: Arsène Druel (arsene.druel@gmail.com)

Received: 12 March 2017 - Discussion started: 28 March 2017

Revised: 25 September 2017 - Accepted: 8 November 2017 - Published: 22 December 2017

\begin{abstract}
Simulation of vegetation-climate feedbacks in high latitudes in the ORCHIDEE land surface model was improved by the addition of three new circumpolar plant functional types (PFTs), namely non-vascular plants representing bryophytes and lichens, Arctic shrubs and Arctic $\mathrm{C}_{3}$ grasses. Non-vascular plants are assigned no stomatal conductance, very shallow roots, and can desiccate during dry episodes and become active again during wet periods, which gives them a larger phenological plasticity (i.e. adaptability and resilience to severe climatic constraints) compared to grasses and shrubs. Shrubs have a specific carbon allocation scheme, and differ from trees by their larger survival rates in winter, due to protection by snow. Arctic $\mathrm{C}_{3}$ grasses have the same equations as in the original ORCHIDEE version, but different parameter values, optimised from in situ observations of biomass and net primary productivity (NPP) in Siberia. In situ observations of living biomass and productivity from Siberia were used to calibrate the parameters of the new PFTs using a Bayesian optimisation procedure. With the new PFTs, we obtain a lower NPP by $31 \%$ (from $\left.55^{\circ} \mathrm{N}\right)$, as well as a lower roughness length $(-41 \%)$, transpiration $(-33 \%)$ and a higher winter albedo (by $+3.6 \%)$ due to increased snow cover. A simulation of the water balance and runoff and drainage in the high northern latitudes using the new PFTs results in an increase of fresh water discharge in the Arctic ocean by $11 \%\left(+140 \mathrm{~km}^{3} \mathrm{yr}^{-1}\right)$, owing to less evapotranspiration. Future developments should focus on the competition between these three PFTs and boreal tree PFTs,
\end{abstract}

in order to simulate their area changes in response to climate change, and the effect of carbon-nitrogen interactions.

\section{Introduction}

Global land surface models are an essential component of Earth system models (ESMs). These land surface models describe the carbon, water and energy exchanges between the land surface and the atmosphere at large spatial scales and a broad range of temporal scales. To this end, surface-vegetation-atmosphere transfer schemes (SVATs, e.g. Henderson-Sellers et al., 1996) were developed and coupled with general circulation models (GCMs) that provide the meteorological forcing used as input to SVATs. Several studies show that the terrestrial biosphere plays an important role in controlling the spatial and temporal distribution of carbon, water and energy fluxes, and thus, indirectly, in modulating regional- to continental-scale climate. In particular, it appears that high-latitude ecosystems have a significant impact on the climate (Bonan, 1995; Christensen et al., 1999; Chapin et al., 2000). For example, circumpolar vegetation changes played an important role in the last glacial inception, i.e. 126.5 to $120 \mathrm{ka}$ (Clark et al., 2009). Reduced tree cover led to an increase in albedo and snow cover, a reduction in temperature and precipitation and ultimately changes in atmospheric circulation and cooling at high latitudes (Gallimore and Kutzbach, 1996; de Noblet et al., 1996; Meissner 
et al., 2003; Vavrus et al., 2008; Colleoni et al., 2009). More recently, Loranty et al. (2014) and Thackeray et al. (2014) reassessed the vegetation control on the snow-albedo feedback at high latitudes, highlighting the important effect of tree and shrub cover on large-scale snow albedo and its often unsatisfying representation in current-generation global climate models. Other critical processes linked to circumpolar vegetation changes are the dynamics of permafrost (Lawrence and Slater, 2005; Koven et al., 2011) and the impact of vegetation cover on momentum and flux exchanges with the atmosphere (Vautard et al., 2010). While the net primary productivity (NPP) and living plant biomass is low at high latitudes because of severe climatic conditions and a short growing season, carbon stocks in high-latitude soils, in particular in permafrost, are very large (e.g. Tarnocai et al., 2009; Hugelius et al., 2011, 2014; Olefeldt et al., 2016) because of reduced decomposition of soil organic matter in soil and the burial of frozen carbon below the active layer over a long period of time. Changing soil properties and temperature in response to future warming could therefore release $\mathrm{CO}_{2}$ and $\mathrm{CH}_{4}$ from thawed permafrost, with a potential carbon release of the order of $92 \pm 17 \mathrm{PgC}$ by 2100 under a strong emission scenario (RCP8.5; Schuur et al., 2015). Altogether, highlatitude vegetation significantly affects regional and global climates and overall leads to positive climate feedbacks (e.g. Pearson et al., 2013). High-latitude vegetation must therefore be correctly represented in ESMs, in particular in the light of projected strong Arctic and sub-Arctic climate warming and related biogeographic shifts. With the current warming trajectory, the colonisation of shrubs could be significant (e.g. Pearson et al., 2013; Frost and Epstein, 2014), and as observed by Blok et al. (2011b) it could lead to an Arctic greening (Blok et al., 2011b; Bonfils et al., 2012) with increased leaf area, decreased surface albedo in winter, and potential increase of temperatures at local and regional scales. For example, based on statistical modelling, Pearson et al. (2013) show that more than half of the vegetated areas of the Arctic are likely to shift to a different physiognomic class by 2050 , with a $>50 \%$ increase in woody cover. However, MyersSmith et al. (2015) have shown that the climate sensitivity of shrub growth is not uniform across the Arctic, indicating a need for detailed physically and physiologically based modelling of high-latitude vegetation changes. Further examples of observations of on-going changes in high-latitude vegetation concern its seasonality, which has been shown to have diminished over the past decades (Xu et al., 2013), and its relationship to interannual climate variability, which has been shown to have weakened (Piao et al., 2014).

In spite of these strong effects of vegetation of the highlatitude climate and the large expected, and in parts already observed, changes of vegetation cover and activity, the description of circumpolar vegetation in land surface models has been relatively simple until recently, and continues to be so in many models, with few plant functional types (PFTs) that share similar equations and differ only by parameter val- ues (except for phenology which is usually PFT-specific). In a recent review, Wullschleger et al. (2014) re-endorse the concept of PFTs for the description of high-latitude vegetation, but also note that surprisingly few dynamic global vegetation models (DGVMs) represent fundamental highlatitude PFTs such as lichen and mosses. In most land surface models (for instance those used in CMIP5 Earth System Models) all vegetation types were classified as either trees or grasses. Taiga and tundra, where non-vascular plants and shrubs dominate the landscapes, cover about $15 \%$ of global land surfaces (Beringer et al., 2001). In the BIOME4 ecosystem model (used specifically to study past and future vegetation transition) the tundra diversity was taken into account (Kaplan et al., 2003) and Chadburn et al. (2015) recently included mosses in the JULES model (Best et al., 2011). Similarly, a first description of lichen and bryophytes was implemented in the JSBACH model (Porada et al., 2013), improved recently with a process-based implementation (Porada et al., 2016). Biogeochemical and biophysical characteristics of shrubs are already implemented in some models, such as in the Community Land Model (Oleson et al., 2013), JULES (Clark et al., 2011) and JSBACH (Baudena et al., 2015). In this study we further develop the ORCHIDEE model (Krinner et al., 2005), the land surface component of the Institute Pierre Simon Laplace (IPSL) ESM, to represent non-vascular plants, Arctic shrubs and tundra grasses. This study focuses on the parameterisations of these three new PFTs, their interactions as part of the DGVM of ORCHIDEE being treated in a subsequent study.

To date, the ORCHIDEE model contains eight different types of trees (tropical broadleaf evergreen and deciduous (raingreen), temperate needleleaf evergreen, broadleaf evergreen and deciduous (summergreen), boreal broadleaf deciduous (summergreen), needleleaf evergreen and deciduous (summergreen)), four types of grasses $\left(\mathrm{C}_{3}\right.$ and $\mathrm{C}_{4}$ grassland as well as $\mathrm{C}_{3}$ and $\mathrm{C}_{4}$ generic crops) and bare soil (Krinner et al., 2005), using the PFT concept. While in ORCHIDEE high-latitude vegetation was represented by a single PFT for $\mathrm{C}_{3}$ grasses and several PFTs for boreal trees, namely boreal broadleaf deciduous, needleleaf deciduous and evergreen conifers (Krinner et al., 2005), in reality it also contains graminoid tundra, shrubs and wetlands including mosses and sedges (see CAVM Mapping Team, 2003). In view of the diversity of circumpolar vegetation, the current discretisation of the vegetation in ORCHIDEE does not allow accurate modelling of the regional dynamics of water, carbon and energy fluxes.

Key PFTs missing in the model for the high latitudes are mosses, lichens and shrubs. Mosses and lichens are nonvascular plants; their uptake of nutrients is not supported by xylem sap flow and their gas exchange of water and $\mathrm{CO}_{2}$ is not regulated by stomata. Moreover, mosses and lichens have different environmental needs than grasses (i.e. more resistant to hydric and thermal stress or to nitrogen limitation). Shrubs are smaller than trees and have a different mor- 
phology, inducing a larger snow accumulation in winter, and tolerance to wind and cold temperature, and therefore have a different potential for colonisation (shrubs being endemic in many tundra ecosystems can grow rapidly in response to warming, whereas trees need to establish).

The aim of the work is to improve the description of circumpolar vegetation in ORCHIDEE in order to allow for a better projection of future climate changes in high latitudes, notably via a more certain quantification of vegetation feedbacks to high-latitude climate change, and a more trustworthy projection of global effects of high-latitude vegetation changes via their impact on the carbon cycle. We added mosses and shrubs and adjusted parameters related to $\mathrm{C}_{3}$ grasses, advancing the representation of the spatial and temporal dynamics of biogeochemical and biophysical processes in the soil-plant-atmosphere continuum. The implementation of the new PFTs is described in Sect. 2. Results obtained both for site-scale and large-scale simulations are described in Sect. 3. Section 4 presents a summary of the key findings together with some perspectives.

\section{Methods}

\subsection{ORCHIDEE: overall model description}

ORCHIDEE describes the exchange of energy, water and carbon between the atmosphere and the biosphere. The model includes the representation of carbon and water exchange at leaf scale up to canopy scale, the allocation of carbon within plant compartments (leaves, roots, heartwood and sapwood), autotrophic respiration, litter production, plant mortality and decomposition of soil organic matter (after Parton et al., 1988). Leaf-scale photosynthesis follows the formulation for $\mathrm{C}_{3}$ plants by Farquhar et al. (1980) and for stomatal conductance by Ball and Berry (Ball et al., 1987) implemented according to Yin and Struik (2009) and Kattge and Knorr (2007), i.e. with a seasonal acclimation of photosynthetic rates to temperature.

The soil hydrology model includes an 11-layer diffusion model following the van Genuchten (1980) equations for texture-dependent hydraulic saturation capacity and vertical diffusivity (de Rosnay et al., 2002). The model runs at halfhourly time steps but describes slow processes such as carbon allocation, respiration, phenology or litter decomposition at time steps of 1 day. ORCHIDEE uses the PFT concept to describe the heterogeneity of land surface ecosystems. Thirteen PFTs (including bare soil) are already present with eight types of trees and two natural and two agricultural herbaceous $\left(\mathrm{C}_{3}\right.$ and $\left.\mathrm{C}_{4}\right)$ types (Krinner et al., 2005), as summarised in Table 1.

The high-latitude version of ORCHIDEE (ORC-HL from ORCHIDEE rev1322) used in this study includes a soilfreezing scheme (Gouttevin et al., 2012) and a three-layer explicit snow model (described initially in Wang et al., 2013).
Table 1. PFTs included in ORCHIDEE. New PFTs incorporated in this study are indicated with asterisks. The deciduous are raingreen in tropical climate and summergreen in others.

\begin{tabular}{llll}
\hline Bare soil & & & \\
\hline Trees & Tropical & $\begin{array}{l}\text { Broadleaf } \\
\text { Broadleaf }\end{array}$ & $\begin{array}{l}\text { Evergreen } \\
\text { Deciduous }\end{array}$ \\
\cline { 2 - 4 } & Temperate & $\begin{array}{l}\text { Needleleaf } \\
\text { Broadleaf } \\
\text { Broadleaf }\end{array}$ & $\begin{array}{l}\text { Evergreen } \\
\text { Evergreen } \\
\text { Deciduous }\end{array}$ \\
\cline { 2 - 4 } & & Beedleleaf & Evergreen \\
& & $\begin{array}{l}\text { Broadleaf } \\
\text { Needleleaf }\end{array}$ & $\begin{array}{l}\text { Deciduous } \\
\text { Deciduous }\end{array}$ \\
\hline Shrubs* & Boreal & Broadleaf* & Deciduous* \\
\hline Grasses & Natural & $\mathrm{C}_{3}$ & Global \\
& & & Arctic* \\
\cline { 2 - 4 } & & $\mathrm{C}_{4}$ & \\
\cline { 2 - 4 } & \multirow{2}{*}{ Crops } & $\mathrm{C}_{3}$ & \\
& & $\mathrm{C}_{4}$ & \\
\hline
\end{tabular}

* Non-vascular $\left(\mathrm{C}_{3}\right)$ plants.

In this new ORCHIDEE version (ORC-HL-VEGv1.0), 3 new PFTs are added to the 13 original ones (Table 1), i.e. nonvascular plants (NVPs) including bryophytes (mosses, liverworts and hornworts) and lichens, boreal shrubs, and boreal $\mathrm{C}_{3}$ grasses.

\subsection{Non-vascular plants (NVPs): bryophytes and lichens}

Bryophytes and lichens (NVPs) have a rather small amount of living biomass, around $200 \mathrm{~g} \mathrm{~m}^{-2}$ (Bond-Lamberty and Gower, 2007; Gornall et al., 2007), but with significant dead organic matter beneath. In contrast, in boreal and tundra ecosystems, where mosses compose a small fraction of total ecosystem biomass, their net primary productivity (NPP) can be up to $50 \%$ of total annual NPP (Viereck et al., 1986; Beringer et al., 2001) corresponding to approximately 1-6\% of the global terrestrial NPP (Ito, 2011; Porada et al., 2013). In addition, NVPs have no sap (i.e. no water circulation), no roots (only rhizoids to hold on to the ground) and no active stomata to optimise the uptake of $\mathrm{CO}_{2}$ in order to minimise water loss.

To represent NVPs the equations of $\mathrm{C}_{3}$ grasses were modified as follows. First, we consider NVP biomass to be represented mainly by leaf carbon (i.e. no wood, reserves and root). Their leaves are assumed to access water in the topsoil without roots (i.e. no carbon allocated to a root compartment). In addition, we modified the equations for photosynthesis and stomatal conductance, carbon allocation, and energy balance (see below). For all other processes and associ- 
ated parameters not described below, we used the $\mathrm{C}_{3}$ grasses equations (as reported by Krinner et al., 2005).

\subsubsection{NVPs: photosynthesis and stomatal conductance}

Photosynthesis of $\mathrm{C}_{3}$ plants in ORCHIDEE is based on Farquhar and Sharkey (1982), with the stomatal conductance $\left(g_{\mathrm{s}}\right)$ implemented according to Yin and Struik (2009):

$g_{\mathrm{s}}=g_{0}+\frac{A+R_{\mathrm{d}}}{C_{\mathrm{i}}+C_{\mathrm{i} *}} \times f_{\mathrm{VPD}}$,

with $g_{0}$ the stomatal conductance when irradiance is null, $A$ the rate of $\mathrm{CO}_{2}$ assimilation, $R_{\mathrm{d}}$ the dark respiration rate, $C_{\mathrm{i}}$ the intercellular $\mathrm{CO}_{2}$ partial pressure and $C_{\mathrm{i} *}$ the $C_{\mathrm{i}}$-based $\mathrm{CO}_{2}$ compensation point in the absence of dark respiration. $f_{\mathrm{VPD}}$ is a function describing the effect of leaf-to-air vapour pressure difference (VPD), described empirically following Yin and Struik (2009):

$f_{\mathrm{VPD}}=\frac{1}{\left[1 /\left(a_{1}-b_{1} \times \mathrm{VPD}\right)-1\right]}$,

with $a_{1}$ and $b_{1}$ empirical constants. This function limits the stomatal conductance under dry air conditions.

Vascular plants have stomata (Kirkham, 2005; Ruszala et al., 2011) to regulate gas fluxes (i.e. $\mathrm{CO}_{2}$, transpiration). For NVPs, the situation is more complex and diverse (Williams and Flanagan, 1996; Chater et al., 2013): some species have "non active" stomata (Ruszala et al., 2011) like Oedipodium, others have only "pseudo-stomata" like Sphagnum, and some have no stomata like Andreaeobryum (Haig, 2013). For the sake of simplicity and given the lack of a well-established photosynthesis model for each NVP type, we considered all NVPs to have "pseudo-stomata". Thus we kept Eq. (1) for $g_{\text {s }}$ (Yin and Struik, 2009) but with a conductance that only weakly depends on the VPD. Observation of NVP transpiration suggests that their conductance has a small dependence on humidity and atmospheric $\mathrm{CO}_{2}$ concentration, but a large mean value. We thus defined the coefficients $a_{1}$ and $b_{1}$ (see Table 2) so that the VPD dependence of leaf stomatal conductance $f_{\text {vpd }}$ in Eq. (2) is almost independent of VPD and chose a large value for $g_{0}$ to simulate a high stomatal conductance. This solution is close to that used by Dimitrov et al. (2011), i.e. a constant conductance.

\subsubsection{NVPs: Plant carbon allocation}

ORCHIDEE has five biomass carbon reservoirs for $\mathrm{C}_{3}$ grasses: leaves, root, reserve, reproductive organs (fruits), and sapwood below and above ground. We chose to keep only the leaf reservoir to represent the NVP biomass and the fruits pool for reproduction (see Table 2). Furthermore, $\mathrm{C}_{3}$ grasses are deciduous vegetation with only reserve pools during wintertime. Using the leaf pool to represent NVP biomass means considering NVPs as an evergreen PFT (see Table 2) with leaves present all year long. The main challenge is then

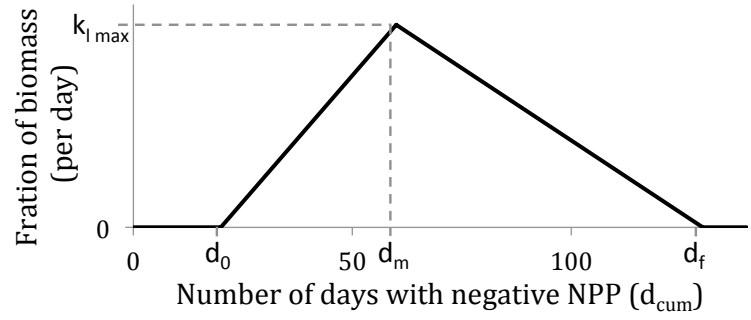

Figure 1. Additional non-vascular biomass loss turnover rate $\left(k_{1}\right.$ in $\mathrm{d}^{-1}$ ) during the non-growing season period when NPP is lower than or equal to zero, starting at 0 on the horizontal axis.

to adapt the leaf biomass turnover rate in order to represent the observed temporal dynamic of lichens and bryophytes biomass.

\subsubsection{NVPs: biomass carbon turnover}

We first modified the original leaf senescence parameter from 120 days (for grasslands) to 470 days for NVPs (Table 2). We then defined an energy cost (i.e. an extra turnover of biomass) for NVP survival in cold winter conditions and limited photosynthesis due to the thickness of the NVPs reducing light penetration.

Bryophytes and lichens have a very good resistance to extreme conditions introduced by lower leaf senescence and no leaf fall. However, this adaptation has an energy and thus a biomass cost, modelled through an additional carbon loss $\left(t_{\mathrm{npp} 0}\right.$ in $\left.\mathrm{gC} \mathrm{m}^{-2} \mathrm{~d}^{-1}\right)$ based on the cumulative number of day $\left(d_{\text {cum }}\right)$ when the NPP is negative or null:

$$
\begin{aligned}
& t_{\mathrm{npp} 0}=b \times k_{1} \\
& k_{1}=\left\{\begin{array}{l}
0, d_{\text {cum }}<d_{0} \\
k_{1 \max } \times \frac{\left(d_{\text {cum }}-d_{0}\right)}{\left(d_{\mathrm{m}}-d_{0}\right)}, d_{0}<d_{\text {cum }}<d_{\mathrm{m}} \\
k_{1 \max } \times \frac{\left(d_{\text {cum }}-d_{f}\right)}{\left(d_{\mathrm{m}}-d_{f}\right)}, d_{\mathrm{m}}<d_{\text {cum }}<d_{f},
\end{array}\right.
\end{aligned}
$$

where $b$ is the (leaf) biomass of NVPs $\left(\mathrm{gC} \mathrm{m}^{-2}\right)$ and $k_{1}$ the additional fraction of biomass lost during extreme conditions (or turnover rate in $\mathrm{d}^{-1}$ ) with a maximum value of $k_{1 \max }$ (in $\left.\mathrm{d}^{-1}\right), d_{0}$ is the threshold delay time (in days) before increasing the turnover, $d_{f}$ (days) the maximum number of days for applying the extra turnover, and $d_{\mathrm{m}}$ (days) the day number when $k_{1}$ reaches its maximum value after $d_{0}$. The values of all parameters are summarised in Table 2. Figure 1 illustrates the increasing biomass turnover linked to extreme conditions with $k_{1}$ as a function of time in the season with negative or zero NPP. After a maximum, the turnover decreases in order to represent the induced resistance and thus survival to extreme conditions, i.e. under snow cover in winter or under dryness.

Using NPP to determine the period of the year with extreme conditions allows us to combine different stress fac- 
Table 2. Non-vascular plant parameters.

\begin{tabular}{|c|c|c|c|}
\hline Parameters & Description & Original $C_{3}$ grasses & Non-vascular plants \\
\hline $\begin{array}{l}\text { Phenotype } \\
\text { organs }\end{array}$ & Organs proportion & $\begin{array}{r}\text { Deciduous } \\
\text { roots, reserves, } \\
\text { leaves, fruits }(10 \%)\end{array}$ & $\begin{array}{r}\text { Evergreen } \\
\text { Leaves }(95 \%), \\
\text { fruits }(5 \%)\end{array}$ \\
\hline$g_{0}\left(\mathrm{Cmol} \mathrm{m}^{-2} \mathrm{~s}^{-1} \mathrm{bar}^{-1}\right)$ & $\begin{array}{l}\text { Stomatal conductance when irradiance } \\
\text { is null }\end{array}$ & 0.00625 & $0.052^{\mathrm{a}}$ \\
\hline$a_{1}(-)$ & Empirical constants & 0.85 (all PFT) & 0.85 \\
\hline$b_{1}(-)$ & Empirical constants & 0.14 & $0.41^{\mathrm{a}}$ \\
\hline Senescence (day) & $\begin{array}{l}\text { Theoretical number of days before } \\
\text { senescence }\end{array}$ & 120 & $470^{\mathrm{a}}$ \\
\hline$d_{0}$ (day) & $\begin{array}{l}\text { Delay before increasing } \\
\text { the turnover (if } \mathrm{NPP} \leq 0 \text { ) }\end{array}$ & - & 20 \\
\hline$d_{\mathrm{m}}($ day) & $\begin{array}{l}\text { Number of days when the fraction } \\
\text { of biomass loss is } \\
\text { maximal (if } \mathrm{NPP} \leq 0 \text { ) }\end{array}$ & - & 60 \\
\hline$d_{f}$ (day) & $\begin{array}{l}\text { Maximum number of days for } \\
\text { this extra turnover } \\
\text { (if } \mathrm{NPP} \leq 0 \text { ) }\end{array}$ & - & 130 \\
\hline$k_{1 \max }($ day) & $\begin{array}{l}\text { Maximal fraction of biomass } \\
\text { loss (if } \mathrm{NPP} \leq 0 \text { ) }\end{array}$ & - & $0.05^{\mathrm{a}}$ \\
\hline $\mathrm{LAI}_{\lim }(-)$ & $\begin{array}{l}\text { Threshold leaf area index } \\
\text { (for turnover) }\end{array}$ & - & $2.4^{\mathrm{a}}$ \\
\hline$l_{\text {coef }}\left(\right.$ day $\left.^{-1}\right)$ & Coefficient & - & $0.014^{\mathrm{a}}$ \\
\hline$r_{\mathrm{p}}(-)$ & $\begin{array}{l}\text { Parameter to control root } \\
\text { profile }\end{array}$ & 4 & $18^{\mathrm{a}}$ \\
\hline$w_{\mathrm{s} \min }(-)$ & $\begin{array}{l}\text { Minimum hydric stress before } \\
\text { any desiccation effect }\end{array}$ & - & 0.8 \\
\hline$d_{\text {off }}(-)$ & Offset of desiccation effect & - & $0.55^{\mathrm{a}}$ \\
\hline$\rho\left(\mathrm{gC} \mathrm{m}^{-3}\right)$ & Density & - & $0.5 \times 10^{4 \mathrm{~b}}$ \\
\hline$C_{\text {dry }}\left(\mathrm{J} \mathrm{m}^{-3} \mathrm{~K}^{-1}\right)$ & Dry soil thermal capacity & 1.80 & $0.29 \times 10^{6}$ \\
\hline$C_{\text {wet }}\left(\mathrm{J} \mathrm{m}^{-3} \mathrm{~K}^{-1}\right)$ & Wet thermal capacity & 3.03 & $4.29 \times 10^{6}$ \\
\hline$C_{\text {ice }}\left(\mathrm{J} \mathrm{m}^{-3} \mathrm{~K}^{-1}\right)$ & Ice thermal capacity & 2.11 & $3.26 \times 10^{6}$ \\
\hline$\lambda_{\text {dry }}\left(\mathrm{W} \mathrm{m}^{-2} \mathrm{~K}^{-1}\right)$ & Dry soil thermal conductivity & 0.4 & 0.092 \\
\hline$\lambda_{\text {sat_wet }}\left(\mathrm{W} \mathrm{m}^{-2} \mathrm{~K}^{-1}\right)$ & Wet thermal conductivity & 0.6 & 0.754 \\
\hline$\lambda_{\text {sat_ice }}\left(\mathrm{W} \mathrm{m}^{-2} \mathrm{~K}^{-1}\right)$ & Ice thermal conductivity & 2.2 & 0.715 \\
\hline$m_{\mathrm{c}(0)}(-)$ & Constant & & 1.178 \\
\hline$m_{\mathrm{c}(1)}(-)$ & Constant & & -1.12 \\
\hline$m_{\mathrm{c}(2)}(-)$ & Constant & & 2.22 \\
\hline$m_{\mathrm{c}(3)}(-)$ & Constant & & -1.40 \\
\hline $\mathrm{LAI}_{\max }\left(\mathrm{m}^{2} \mathrm{~m}^{-2}\right)$ & Maximum leaf area index & 2 & $3.06^{\mathrm{a}, \mathrm{c}}$ \\
\hline $\mathrm{Vc}_{\max (25)}\left(\mu \mathrm{mol} \mathrm{m} \mathrm{s}^{-2} \mathrm{~s}^{-1}\right)$ & $\begin{array}{l}\text { Maximum rate of carboxylation } \\
\text { at } 25^{\circ} \mathrm{C}\end{array}$ & 70 & $28^{\mathrm{a}}$ \\
\hline $\operatorname{SLA}\left(\mathrm{m}^{2} \mathrm{gC}^{-1}\right)$ & Specific leaf area & $2.6 \times 10^{-2}$ & $0.84 \times 10^{-2 \mathrm{a}}$ \\
\hline$f_{\mathrm{m} \_ \text {resp }}\left(\mathrm{gC} \mathrm{gC}^{-1} \mathrm{day}^{-1}\right)$ & $\begin{array}{l}\text { Maintenance respiration coefficient } \\
\text { at } 0^{\circ} \mathrm{C}\end{array}$ & $2.62 \times 10^{-3}$ & $2.57 \times 10^{-3 a}$ \\
\hline
\end{tabular}

${ }^{a}$ Optimised parameter (see Sect. 2.6.1). ${ }^{\mathrm{b}}$ Estimated from Yoshikawa et al. (2002) and O'Donnell et al. (2009). ${ }^{\mathrm{c}}$ Estimated from Bond-Lamberty and Gower (2007).

tors such as cold temperature and very low moisture. Hence, the combination of short-term stress episodes (periods when $d_{0}>0$ ) such as a short drought followed by a snowfall (blocking of light and cold temperature stress) on the NVPs could result in a long-term impact (increase in turnover) on vegetation.
The second turnover rate is related to favourable conditions with a large growth of biomass during the growing season (such as in peatlands). Given their large NPP under favourable conditions, NVPs can accumulate biomass over several tens of centimetres. In this case, sunlight cannot reach the lower portion of the canopy due to light penetration de- 
creasing, although this biomass is still considered as leaf material (see Sect. 2.2.1). The underneath biomass usually dies from a lack of light and possibly a lack of oxygen in wet conditions. Given that oxygen concentration is not simulated in this model, the effect of anoxic conditions and severe light limitation are simply parameterised by increasing the overall leaf biomass turnover rate during the growing season. We chose the leaf area index (LAI) to define this additional turnover: when the maximum LAI $\left(\mathrm{LAI}_{\text {lim }}\right)$ is reached, the underlying layers will not receive any sunlight, resulting in an increase of their turnover rate $\left(t_{\text {missL }}\right)$ represented by

$t_{\text {missL }}=b \times\left(e^{1_{\text {coef }} \times\left(\mathrm{LAI}-\mathrm{LAI}_{\text {lim }}\right)}-1\right)$ if $\mathrm{LAI}>\mathrm{LAI}_{\mathrm{lim}}$,

where $b$ is the leaf biomass of NVPs $\left(\mathrm{gC} \mathrm{m}^{-2}\right), l_{\text {coef }}$ a coefficient $\left(\mathrm{d}^{-1}\right)$ and $\mathrm{LAI}_{\text {lim }}$ a threshold leaf area index. These two parameters are optimised in Sect. 2.6.1 and their values reported in Table 2 .

\subsubsection{Water access}

\section{Plant water uptake}

In ORCHIDEE, all vegetation types have access to soil water through a root system. The ability of roots to extract water depends on soil moisture in the different soil layers (11 currently, see Sect. 2.1) and the root density profile ( $R$; de Rosnay, 1999):

$$
R(z)=e^{-r_{\mathrm{p}} \times z}
$$

with $z$ the soil depth (in metres) and $r_{\mathrm{p}}$ a PFT-dependent parameter to control the shape of the root profile.

NVPs do not have roots to absorb water (or nutrients from the underlying substrate). Some of them, such as Sphagnum, can have threadlike rhizoids, but only to anchor to the soil. So they can only access the surrounding surface water. However, ORCHIDEE does not include a surface liquid water reservoir; thus for simplicity we have assumed that NVPs have access to water stored in the first top-soil layers. This assumption allows us to keep an internal coherence between PFTs and facilitates the treatment of competition for water between PFTs. The value of the $r_{\mathrm{p}}$ parameter (Table 2) for NVPs was defined through the optimisation (see Sect. 2.6.1). With $50 \%$ water uptake (without roots) at $2.5 \mathrm{~cm}$ and $95 \%$ at $11 \mathrm{~cm}$, we obtained water access values close to those proposed by Dimitrov et al. (2011) and Chadburn et al. (2015). Figure 2 illustrates the soil water uptake profile for NVPs, and the root profiles for $\mathrm{C}_{3}$ grasses and boreal trees (used in ORCHIDEE).

\section{Impact of drought on the desiccation of NVPs}

During and after a water stress period, the water content of NVPs decreases significantly (desiccation), which reduces the plant photosynthetic capacity (Williams and Flanagan,

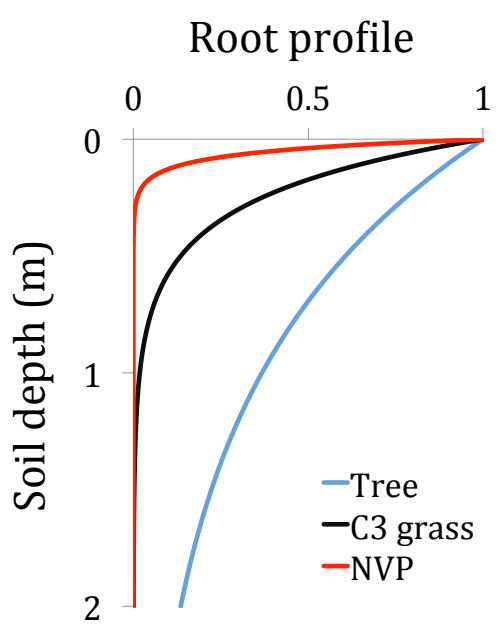

Figure 2. Root profile of boreal broadleaf trees, $\mathrm{C}_{3}$ grasses and soil water uptake profile for NVPs.

1996; Wania et al., 2009; Dimitrov et al., 2011). As for the other PFTs in ORCHIDEE, the instantaneous effect of soil water limitation will reduce photosynthesis through a soil water stress function imposed on the maximum photosynthetic capacity (Farquhar et al., 1980 photosynthesis model). Additionally, for NVPs, plant desiccation occurs and the time needed before recovery to optimum photosynthetic capacity must be taken into account.

To account for this effect, Wania et al. (2009) reduced gross primary production as a function of the annual mean water table position. In ORC-HL-VEGv1.0 we chose to use a monthly running mean hydric stress factor $\left(w_{\mathrm{s}}\right)$ computed from the relative water content in each soil layer weighted by the specific water uptake profile of NVPs defined in Fig. 2. We defined a desiccation function, $d_{\mathrm{ess}}$, as a linear function of $w_{\mathrm{s}}$ (Eq. 6 and Fig. 3) varying between 1 (no impact) and a minimum value $d_{\text {off }}$, when $w_{\mathrm{s}}$ decreases to zero under maximum water stress. The function $d_{\mathrm{ess}}\left(w_{\mathrm{s}}\right)$ illustrated in Fig. 3 scales the maximum rate of carboxylation $\left(\mathrm{Vc}_{\max }\right)$ as well as the maintenance respiration. The maximum rate of electron transport $\left(\mathrm{Vj}_{\max }\right)$ is scaled through $\mathrm{Vc}_{\max }$. Indeed, leaf maintenance respiration defined in ORCHIDEE being a function of the leaf carbon content (biomass) and LAI, should then be reduced when NVPs get desiccated. With this formulation, we can take into account the impact of a drought on a monthly timescale:

$d_{\mathrm{ess}}=\left\{\begin{array}{l}d_{\mathrm{off}}+\frac{1-d_{\mathrm{off}}}{w_{\mathrm{smin}}} \times w_{\mathrm{s}}, \text { if } w_{\mathrm{s}}<w_{\mathrm{s} \min } \\ 1, \quad \text { if } w_{\mathrm{s}} \geq w_{\mathrm{s} \min },\end{array}\right.$

with $w_{\text {s min }}$ being the minimum threshold hydric stress for desiccation (a constant defined in Table 2). 


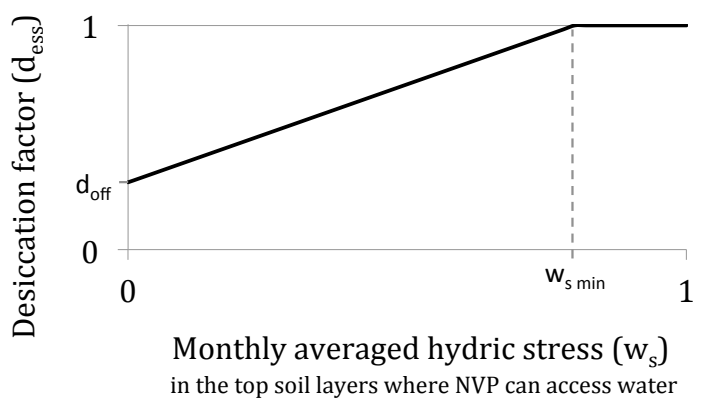

Figure 3. Desiccation function for Non-Vascular Plants.

\subsubsection{NVPs: heat transfers}

Non-vascular plants, and more precisely bryophytes, form an insulating layer above the soil with thus a strong control on the heat exchange between the atmosphere and the soil (Dyrness, 1982; Beringer et al., 2001; Blok et al., 2011a). In its standard version, ORCHIDEE does not account for the thermal insulation properties of vegetation in the calculation of the surface energy budget. For the sake of simplicity and following the same approach as in Chadburn et al. (2015), we modified in ORC-HL-VEG the upper soil layer characteristics to describe the effects of NVPs on the heat transfers to the soil over a depth that is equivalent to the NVP thickness and for the fraction of each grid cell covered by NVPs.

First we estimate the thickness of NVPs $(h)$ assuming a fixed biomass density:

$h=\frac{b}{\rho}$,

with $b$ the total NVP biomass $\left(\mathrm{g} \mathrm{m}^{-2}\right)$ and $\rho$ its density $\left(\mathrm{gC} \mathrm{m}^{-3}\right.$; see Table 2).

The thermal capacity/conductivity (Eqs. 8 and 9) of the upper soil layers (equivalent to the depth of the NVP layer) are modified based on the soil volumetric moisture content (as in the standard ORCHIDEE version) and the heat conductivity and capacity of NVPs, following Soudzilovskaia et al. (2013). The heat thermal capacity of the top-soil thickness $h$ occupied by NVPs, $C$, follows from

$C=C_{\mathrm{dry}}+m_{\mathrm{vol}} \times\left(C_{\mathrm{wet}}-C_{\mathrm{dry}}\right)$,

where $m_{\mathrm{vol}}$ is the volumetric relative moisture content over a thickness $h, C_{\text {dry }}$ the dry thermal capacity of dry NVPs and $C_{\text {wet }}$ the wet heat capacity of wet NVPs (from Soudzilovskaia et al., 2013; see Table 2). Note that in the standard case without NVPs, $C_{\text {wet }}$ and $C_{\text {dry }}$ are defined from the soil texture (see Wang et al., 2016). In the case of frozen soil we use an ice capacity $\left(C_{\text {ice }}\right)$ for NVPs, deduced relative to the $C_{\text {ice }}$ of soil. When the soil is partly frozen a weighting average between the two thermal capacities is calculated (using $x$, the unfrozen soil fraction). The overall thermal con- ductivity, $\lambda$, follows from

$\lambda=\lambda_{\mathrm{dry}}+m_{\mathrm{vol}} \times\left(\lambda_{\mathrm{sat}}-\lambda_{\mathrm{dry}}\right)$

$\lambda_{\text {sat }}=\lambda_{\text {sat_wet }}^{x} \times \lambda_{\text {sat_ice }}^{1-x}$,

with $\lambda_{\text {dry }}$ being the dry soil thermal conductivity, $\lambda_{\text {sat_wet }}$ the unfrozen wet thermal conductivity (from Soudzilovskaia et al., 2013) and $\lambda_{\text {sat_ice }}$ the frozen thermal conductivity of NVPs (derived relative to the $\lambda_{\text {sat_ice }}$ of soil). See Table 2 for values and units. Note that the current version of ORCHIDEE only calculates one energy budget (being the average of all vegetation types present in a grid cell); the overall thermal soil characteristics thus correspond to a weighted average of the soil characteristics according to the fraction of NVPs covering a grid cell.

\subsubsection{NVPs: soil organic matter decomposition}

In the standard version of ORCHIDEE, two important factors, temperature and moisture, exert control over litter and soil organic matter decomposition (following the CENTURY model; Parton et al., 1988). These factors are computed from weighted mean soil temperature and soil moisture profiles, assuming an exponential profile of soil organic matter content and associated decomposition processes between 0 and $2 \mathrm{~m}$ depth. For the moisture control of decomposition, the original function (Parton et al., 1988; Krinner et al., 2005) is increasing with soil moisture content (maximum at saturation), which is not adapted for water-saturated soils, where anoxic conditions reduce soil microorganism activity (such as in peatlands). As these conditions may prevail for NVP covers, we modified the original scheme.

First, we introduced a vertical discretisation of belowground litter carbon pools, assuming it follows the same distribution as the root profile for vascular plants or soil water uptake profile for NVPs (exponential decay as Eq. (5), in de Rosnay, 1999), as in Frolking et al. (2001). Moreover, we consider that there is no above-ground litter for NVPs, so that leaf litter is treated like below-ground litter, as in Frolking et al. (2001) and Chadburn et al. (2015). With this new vertical discretisation, we chose to use the temperature and soil moisture of each layer to control litter decomposition.

To account for anoxic conditions often prevailing in watersaturated NVP ecosystems causing slow decomposition rates (Frolking et al., 2001), we changed the moisture decomposition function $\left(R_{\mathrm{SR}}\right)$ applied for each layer as in Moyano et al. (2012), using a look-up table approach. Equation (10) and Fig. 4 describe the new function and the reduced decomposition with soil moisture content (applied for the litter from all 
PFTs):

$$
\begin{aligned}
& \operatorname{PR}_{\mathrm{SL}}\left(m_{\mathrm{vol}}\right)=m_{\mathrm{c}(3)} \times m_{\mathrm{vol}}^{3}+m_{\mathrm{c}(2)} \times m_{\mathrm{vol}}^{2} \\
& +m_{\mathrm{c}(1)} \times m_{\mathrm{vol}}+m_{\mathrm{c}(0)} \\
& \mathrm{SR}\left(m_{\mathrm{vol}}\right)=\prod_{k=0}^{m_{\mathrm{vol}}} \operatorname{PR}_{\mathrm{SL}}(k) \\
& R_{\mathrm{SR}}\left(m_{\mathrm{vol}}\right)=\frac{\mathrm{SR}\left(m_{\mathrm{vol}}\right)}{\max _{0<k<1}(\mathrm{SR}(k))}
\end{aligned}
$$

with SR being the soil respiration (coefficient), $\mathrm{PR}_{\mathrm{SR}}$ the proportional response of SR to soil moisture, $R_{\mathrm{SR}}$ the relative respiration, $m_{\mathrm{vol}}$ the soil volumetric moisture content (unitless), and $m_{\mathrm{c}(1-3)}$ three parameters taken from Moyano et al. (2012). SR is equal to the product of all PR $\mathrm{SL}_{\mathrm{SL}}$ values (denoted by $\Pi$ symbol) at each 0.01 moisture interval $(k)$, from zero to the computed SR moisture. To obtain $R_{\mathrm{SR}}, \mathrm{SR}$ is divided by the maximum of SR for all $k$ intervals ( 0 to 1$)$. See Table 2 for constant values. Note that the temperature function decomposition is not modified.

\subsubsection{NVPs: summary and other parameters}

Other parameters and processes used for NVPs are set equal to those of $\mathrm{C}_{3}$ grasses, such as albedo and roughness as described by Krinner et al. (2005). We have optimised specific parameters of NVPs (marked with an "a" in Table 2) against observation (see Sect. 2.5.1), following a Bayesian optimisation framework (see Sect. 2.6.1). The values of the main parameters for the NVPs including the optimised ones are reported in Table 2 .

\subsection{Boreal deciduous shrubs}

Shrubs share biogeochemical and biophysical processes with trees. Therefore, the introduction of a new shrub PFT is based on the equations for boreal deciduous broadleaf tree PFT. The main difference between trees and shrubs concerns the size, and thus the allometry resulting from carbon allocation. Furthermore, shrubs grow faster and therefore colonise landscapes before trees do. For high latitudes, the cold protection of shrubs by snow is an important process that needs to be taken into account, since snow depth and shrub height are positively correlated (McFadden et al., 2001; Sturm et al., 2001). Snow cover tends to be thicker when shrubs are present (McFadden et al., 2001), and a thicker snow cover better protects shrubs from frost damage.

Note that all modifications made here are generic so that we can easily create additional shrub types, such as needleleaf or evergreen phenotype, with only few parameter changes.

\subsubsection{Shrubs: allometry}

Tree allometry in ORCHIDEE is based on a pipe tune model (Smith et al., 2001). It represents the relation between height and diameter as a power (or log-linear) function, with no height limit. Shrub development is more horizontal than vertical (Bentley et al., 1970; Sitch et al., 2003; Lufafa et al., 2009), which requires modification of the tree allometry. We implemented the allometry rules described by Aiba and Kohyama (1996) with specific values for shrubs from Martínez and López-Portillo (2003). Equation (11) gives the allometry relation between individual height $(H$, in metres), diameter $\left(D\right.$, in metres), volume $\left(V, \mathrm{~m}^{3}\right)$, the number of individuals $\left(n_{\mathrm{i}}\right)$, the total crown area $\left(C_{\mathrm{a}}, \mathrm{m}^{2}\right)$, the total stem basal areal $\left(T, \mathrm{~m}^{2}\right)$, the total woody biomass $\left(m_{\mathrm{w}}, \mathrm{gC}^{-2}\right)$ and wood density ( $\rho_{\mathrm{w}}$, between 0 and 1$)$. The height of a shrub is related to a logarithmic function of its diameter (Eq. 11a) and its volume is represented by a cylinder (Eq. 11b). The shrub vegetation cover is defined as a function of the total stem basal area (Eq. 11c). With simple geometric relations (Eq. 11d) and assuming a fixed crown area $\left(C_{\mathrm{a}}\right.$ becomes a constant) the system can be solved and all key variables expressed as a function of shrub woody biomass $\left(m_{\mathrm{W}}\right)$. The height is given by Eq. (11e) and the number of individuals is adapted in order to keep the crown area fixed (Eq. 11c and d). If the crown area is not fixed (e.g. with dynamic vegetation), there is no analytical solution to obtain the height:

$$
\begin{aligned}
& 1 / H=1 /\left(A \times D^{\gamma}\right)+1 / H_{\max } \\
& V=\pi / 4 \times \frac{H_{\max } \times A \times D^{2+\gamma}}{H_{\max }+A \times D^{\gamma}} \\
& C_{\mathrm{a}}=\beta \times T^{\alpha}=\beta \times\left(n_{\mathrm{i}} \times \pi / 4 \times D^{2}\right)^{\alpha} \\
& m_{\mathrm{w}}=n_{\mathrm{i}} \times V \times \rho_{\mathrm{w}} \text { and } H=\frac{n_{\mathrm{i}} \times V}{T} \\
& H=\frac{m_{\mathrm{w}}}{\rho_{\mathrm{w}} \times\left(C_{\mathrm{a}} / \beta\right)^{1 / \alpha}},
\end{aligned}
$$

where $A, \beta, \gamma, \alpha$ and $H_{\max }$ are parameters adapted from Martínez and López-Portillo (2003) (see Table 4). Here, the parameter $H_{\max }$ defining the maximal height (in metres) was optimised (see Sect. 2.6.1). In accordance with imposed vegetation coverage, a minimum woody vegetation height $\left(H_{\mathrm{min}}\right.$, in metres) was prescribed based on the maximum height, according to

$H_{\min }=H_{\max } / h_{\mathrm{c}}$

where $h_{\mathrm{c}}$ is a factor defined in Table 4. Based on the new shrub allometry equations (Eq. 11), new parameters can be derived for shrubs with the pipe tune model (Table 4).

\subsubsection{Shrubs: impact on snow}

Shrub vegetation affects snow cover through snow compaction and spatial heterogeneity of snow deposition (due to lateral wind transport). Shrub (and tree) branches support part of the snow cover. As a result, the snow weight on lower snow layers is smaller and the compaction of snow crystals is reduced. Moreover, wind is reduced by the presence of 
Table 3. Snow compaction parameters. Original values are from Wang et al. (2013), and herbaceous and high vegetation values are chosen to stay in the value range proposed by Wang et al. (2013).

\begin{tabular}{llrrr}
\hline Parameters & Description & $\begin{array}{r}\text { Original } \\
\text { values }\end{array}$ & $\begin{array}{r}\text { Ground vegetation } \\
\text { (bare soil, grasses and NVPs) }\end{array}$ & $\begin{array}{r}\text { High vegetation } \\
\text { (shrubs and trees) }\end{array}$ \\
\hline$a_{\mathrm{sc}}$ & Snow settling parameter $\left(\mathrm{s}^{-1}\right)$ & $2.8 \times 10^{-6}$ & $1.4 \times 10^{-6}$ & $4.2 \times 10^{-6}$ \\
$b_{\mathrm{sc}}$ & Snow settling parameter $\left(\mathrm{K}^{-1}\right)$ & 0.04 & 0.02 & 0.06 \\
$c_{\mathrm{sc}}$ & Snow settling parameter $\left(\mathrm{m}^{3} \mathrm{~kg}^{-1}\right)$ & 460 & 230 & 690 \\
$a_{\eta}$ & Snow Newtonian viscosity parameter $\left(\mathrm{K}^{-1}\right)$ & 0.081 & 0.0405 & 0.12 \\
$b_{\eta}$ & Snow Newtonian viscosity parameter $\left(\mathrm{m}^{3} \mathrm{~kg}^{-1}\right)$ & 0.018 & 0.009 & 0.027 \\
$\eta_{0}$ & Snow Newtonian viscosity parameter $(\mathrm{Pa} \mathrm{s})$ & $3.7 \times 10^{7}$ & $1.85 \times 10^{7}$ & $5.55 \times 10^{7}$ \\
\hline
\end{tabular}

a shrub (and tree) canopy, which further reduces snow compaction compared to short vegetation cover. We kept the original snow compaction equation in ORCHIDEE (Wang et al., 2013, their Eqs. 11, 12 and Table A1) but chose new values for the parameters controlling compaction depending upon low or high vegetation (Table 3 ) in order to model a different depth and density over the fraction of a grid cell covered with shrubs (and tree).

Currently there is no sub-grid simulation of snow cover and energy balance in ORCHIDEE, so there is no distinction according to the fraction of different PFTs present in a grid cell. To account for differences between PFTs we computed snow compaction separately for short vegetation (bare soil, grasses and NVPs), shrubs and trees. The resulting average snow depth and density over a grid cell is obtained by weighting each vegetation-dependent compaction by its fraction. The deposition of snow is assumed to be identical among the different PFTs. A PFT-dependent snow depth is needed to compute the protection of vegetation by snow (Sect. 2.3.3). To compensate for the lack of an explicit PFTdependent snow depth, an empirical correction is applied to account for the effect of vegetation type on snow compaction and deposition on shrubs:

$d_{\mathrm{s} \_\mathrm{v}}=d_{\mathrm{s}_{-} \mathrm{f}} \times d_{\mathrm{s}}$

$d_{\mathrm{s}_{\mathrm{f}} \mathrm{f}}= \begin{cases}1+f_{\mathrm{v}}, & f_{\mathrm{v}} \leq 0.5 \\ 2-f_{\mathrm{v}}, & f_{\mathrm{v}}>0.5\end{cases}$

with $d_{S_{-} v}$ being the snow depth of high vegetation (shrubs and trees, in metres), $d_{\mathrm{s}}$ the average snow depth (in metres) over the grid-cell, and $d_{\mathrm{s}_{\mathrm{f}}}$ a function of $f_{\mathrm{v}}$, the fraction of high vegetation. Note that this equation is a heuristic formulation discussed in Sect. 4.

\subsubsection{Shrubs: mortality reduction by snow protection}

ORCHIDEE includes a tree mortality during extremely cold days, calculated as the percentage of biomass lost at the end of each day, when used to compute the vegetation distribution dynamically (see Zhu et al., 2015). This mortality depends on a minimum temperature, as defined in Eq. (14). We used the same equation but assigned a critical minimum survival temperature to all boreal (including needleleaf) trees:

If $T_{\min }<T_{\min , \text { crit }}, M_{\mathrm{ce}}=k_{\mathrm{ce}} \times\left(T_{\min , \text { crit }}-T_{\min }\right)$,

with $M_{\mathrm{ce}}$ being the mortality rate due to cold extremes, $T_{\text {min,crit }}$ the minimum critical survival temperature (defined for each PFT), $T_{\min }$ the daily minimum air temperature and $k_{\mathrm{ce}}$ a mortality coefficient. The values of these parameters are given in Table 4.

For shrubs we used a similar approach to control for loss of biomass due to extreme cold temperatures. A mortality rate similar to Eq. (14) is applied to the highest parts of shrubs that are not covered by snow. For the part of shrubs situated inside snow layers (see Sect. 2.3.2 and Eq. 13 for the shrub snow depth calculation), snowpack temperature is used in Eq. (15). We defined a daily vertical profile of the minimum temperature $T_{\min }(z)$ function of shrub height above ground $(z)$, by linear interpolation between soil, snow layers and air temperatures above the shrub height emerging from the snow pack. To simulate the mortality of shrub parts being exposed to extreme cold, the following mortality equation is applied for the top part of shrubs:

$$
\begin{aligned}
& M_{\mathrm{ce}}=\int_{H_{\min }}^{H} \frac{k_{\mathrm{ce}} \times f n(T)}{H} \mathrm{~d} z \\
& f_{\mathrm{n}}(z)=\left\{\begin{array}{l}
0, T_{\min } \geq T_{\min \text { crit }} \\
T_{\text {min crit }}-T_{\min }(z) T_{\min }<T_{\text {min crit }},
\end{array}\right.
\end{aligned}
$$

with $M_{\text {ce }}$ being the extreme cold mortality, $T_{\min c r i t}$ a minimum critical temperature (defined by PFT), $k_{\mathrm{ce}}$ a coefficient, $H$ the shrub height and $H_{\min }$ its minimum height (Eq. 12). The values of the parameters of Eq. (14) for shrubs are given in Table 4. This equation is the integral of Eq. (14) applied to the height of shrubs.

\subsubsection{Shrubs: modification of roughness and albedo}

In ORCHIDEE, the surface roughness length is directly computed from the height of the vegetation. Similarly, surface albedo depends on the vegetation type. Because shrubs can be partially or entirely covered by snow, the computation 
Table 4. Shrub parameters.

\begin{tabular}{|c|c|c|c|c|}
\hline \multicolumn{5}{|c|}{ Allometry } \\
\hline \multirow[t]{2}{*}{ Parameters } & \multirow[t]{2}{*}{ Description } & \multirow{2}{*}{$\begin{array}{r}\text { Trees } \\
\text { Pipe tune }\end{array}$} & \multicolumn{2}{|r|}{ Shrubs } \\
\hline & & & $\begin{array}{r}\text { Pipe tune } \\
\text { (like trees) }\end{array}$ & $\begin{array}{r}\text { Aiba and Kohyama } \\
(1996)^{\mathrm{b}}\end{array}$ \\
\hline$A$ & Allometry constant & - & - & 0.75 \\
\hline$\beta$ & Allometry constant & 40.0 & 8.0 & $\log (\beta)=2.42$ \\
\hline$\gamma$ & Allometry constant & 0.5 & 0.55 & 1.15 \\
\hline$\alpha$ & Allometry constant & 100.0 & 216.9 & 0.8 \\
\hline$\delta$ & Allometry constant & 1.6 & 1.6 & - \\
\hline$H_{\max }(\mathrm{m})$ & Maximum height & 15 & $3.5 *$ & $3.5 *$ \\
\hline$H_{f \_ \text {dia }}(0-1)$ & $\begin{array}{l}\text { Maximum height used to } \\
\text { compute the diameter }\end{array}$ & - & - & 0.90 \\
\hline$h_{\mathrm{c}}$ & Minimum height factor & 10 & 10 & 10 \\
\hline \multicolumn{5}{|c|}{ Other parameters } \\
\hline Parameters & Description & Trees & & Shrubs \\
\hline$k_{\mathrm{ce}}(-)$ & $\begin{array}{l}\text { Coefficient of mortality due } \\
\text { to extreme coldness }\end{array}$ & 0.04 & & 0.04 \\
\hline$T_{\min , \text { crit }}\left({ }^{\circ} \mathrm{C}\right)$ & Minimum critical temperature & -45 & & -45 \\
\hline$z_{0 \_} \mathrm{c}(\mathrm{m})$ & Roughness constant & 16 & & 16 \\
\hline$z_{0 \_}$bs $(\mathrm{m})$ & Roughness of the bare soil & 0.01 & & 0.01 \\
\hline$\Delta_{z_{0}}(-)$ & $\begin{array}{l}\text { Width of the transition zone when } \\
d_{\mathrm{S}} \text { is around } H_{\mathrm{PFT}}\end{array}$ & 0.3 & & 0.3 \\
\hline$\xi(-)$ & Snow fraction constant & 5 & & 5 \\
\hline $\operatorname{SLA}\left(\mathrm{m}^{2} \mathrm{gC}^{-1}\right)$ & Specific leaf area & $2.6 \times 10^{-2}$ & & $2.7 \times 10^{-2 \mathrm{a}}$ \\
\hline $\operatorname{LAI}_{\max }\left(\mathrm{m}^{2} \mathrm{~m}^{-2}\right)$ & Maximum leaf area index & 4.5 & & $2.5^{\mathrm{a}}$ \\
\hline $\mathrm{Vc}_{\max (25)}\left(\mu \mathrm{mol} \mathrm{m}{ }^{-2} \mathrm{~s}^{-1}\right)$ & Maximum rate of carboxylation at $25^{\circ} \mathrm{C}$ & 45 & & $38^{\mathrm{a}}$ \\
\hline Residence Time (years) & & 80 & & $32^{\mathrm{a}}$ \\
\hline$f_{\text {g_resp }}(0-1)$ & $\begin{array}{l}\text { Fraction of GPP which is lost } \\
\text { as growth respiration }\end{array}$ & 0.28 & & $0.59^{\mathrm{a}}$ \\
\hline
\end{tabular}

a Optimised parameter (see Sect. 2.6.1). ${ }^{\mathrm{b}}$ Adapted from Martínez and López-Portillo (2003).

of surface roughness and albedo in the presence of shrubs needs to take into account snow height. The calculation of surface roughness length has thus been modified. First vegetation height is computed separately for shrubs (using Eq. 11) and for trees (using the original pipe tune model equation of Smith et al., 2001). The height of the snow cover over shrubs is then subtracted from the vegetation height in order to estimate the height of the vegetation above the snow surface (i.e. the relative height), which determines the surface roughness. The relative difference between the relative height and the total height is not substantial for trees (height $>5 \mathrm{~m}$ ), but it can be important for shrubs $(>30 \mathrm{~cm})$, which can be totally covered by snow. To represent the spatial heterogeneity of snow cover, when the snow thickness is close to the height of vegetation, a linear function is applied to estimate the height above snow:

$H_{\mathrm{PFT}_{\mathrm{as}}}=\left\{\begin{array}{l}H_{\mathrm{PFT}}-d_{\mathrm{s}}, \text { if } H_{\mathrm{PFT}}>d_{\mathrm{s}} \times\left(1+\Delta_{z_{0}}\right) \\ 0, \text { if } H_{\mathrm{PFT}}<d_{\mathrm{s}} \times\left(1-\Delta_{z_{0}}\right) \\ \left(H_{\mathrm{PFT}}-d_{\mathrm{s}}\left(1-\Delta_{z_{0}}\right)\right) / 2, \text { otherwise }\end{array}\right.$ where $H_{\mathrm{PFT}}$ is the height of the PFT, $H_{\mathrm{PFT} \_ \text {as }}$ is the height of the PFT above the snow, $d_{\mathrm{s}}$ is depth of snow, and $\Delta_{z_{0}}$ the width of the transition zone due to spatial heterogeneity of snow cover (see Table 4).

The fraction of vegetation $\left(f_{\mathrm{v}}\right)$ is used to compute the roughness length $z_{0}$. For trees and shrubs the maximum fraction of vegetation $f_{\mathrm{v}}=f_{\mathrm{v} \_} m_{\mathrm{ax}}$ (prescribed if the vegetation cover is static, or calculated when the vegetation cover is dynamic, and independent of LAI) is used to take into account the influence of trunks and branches even if there are no leaves. For grasses and NVPs, to take into account the variation of leaf cover (for example absent for grasses in winter) only the projected surface of the foliage in the canopy $f_{\mathrm{v}}=f_{\mathrm{V} \_ \text {max }}\left(1-e^{-\mathrm{LAI} / 2}\right)$ is used because there are no woody elements. The rest of the surface is treated as bare soil with a constant roughness length value.

Finally the roughness length of a given PFT is calculated as its height above snow multiplied by a roughness parameter $z_{0 \_}$, as initially in ORCHIDEE. If this value is lower than 
the bare soil roughness ( $z_{0}$ bs fixed), then the latter value is used. The grid cell mean roughness length is computed (from Vihma and Savijärvi, 1991) as a function of each PFT roughness weighted by the vegetation cover, $f_{\mathrm{v}}$ :

$\log \left(z_{0}\right)=\sum_{\text {PFT }}\left(f_{\mathrm{v}} \times \log \left(\max \left(\frac{H_{\text {PFT_as }}}{z_{0 \_c}}, z_{0 \_ \text {bs }}\right)\right)\right)$,

where $z_{0}$ is the grid-cell averaged roughness $(\mathrm{m}), z_{0}$ bs the roughness of the bare soil $(\mathrm{m}), f_{\mathrm{v}}$ the fraction of each PFT and $z_{0}$ c a constant roughness parameter. The values of the parameters of Eq. (17) are given in Table 4.

The mean albedo of a grid cell depends on the vegetation, bare soil and snow albedo and their fractional coverage. While snow albedo is a function of snow age (computed for each vegetation type), bare soil and vegetation albedo are constant in time. A critical parameter to weigh the different terms is the fraction of the grid cell covered by snow, snow $_{\text {frac }}$, on bare soil and vegetation. In ORCHIDEE this fraction only depends on the snow mass, as defined in Chalita and Le Treut (1994). We chose to modify this approach in order to account for the effect of the vegetation structure as in Douville et al. (1995) and Boone (2002), using the roughness length calculated from Eq. (17), which is given by

snow $_{\text {frac }}=\frac{\operatorname{snow}_{\mathrm{d} z}}{\operatorname{snow}_{\mathrm{d} z}+\xi \times z_{0}}$,

with snow frac being the fraction of the grid covered by snow, snow $_{\mathrm{d} z}$ the snow thickness, $z_{0}$ the roughness length and $\xi$ a parameter (defined in Table 4).

\subsubsection{Shrubs: parameters}

Table 4 summarises the main parameter values used in the equations described previously as well as a few other parameters modified for the shrub PFT (compared to the initial tree PFT).

\subsection{Cold climate $\mathrm{C}_{3}$ grasses}

In order to better account for biogeochemical differences between Arctic, temperate and tropical grasses (only one PFT in ORCHIDEE), we re-parameterised the grassland PFT for circumpolar regions, following the generic equations of $\mathrm{C}_{3}$ grasses. A number of parameters have been calibrated (see list in Table 5) to modify primarily the photosynthetic activity, the root distribution in the soil and the leaf development.

The rate of carboxylation, limited by Rubisco $\left(V_{\mathrm{c}}\right)$ and electron transport $\left(V_{j}\right)$, is dependent on specific parameters (following Yin and Struik, 2009 and presented in Eq. 19), themselves functions of monthly mean temperature $\left(t_{\mathrm{m}}\right.$, in kelvin; see Eq. 20):

$$
F(T)=k_{25} \times e^{\frac{E_{\mathrm{a}} \times\left(T-T_{25}\right)}{T_{25} \times R \times T}} \times \frac{1+e^{\frac{T_{25} \times \Delta S-E_{\mathrm{d}}}{T_{25} \times R}}}{1+e^{\frac{T \times \Delta S-E_{\mathrm{d}}}{T \times R}}},
$$

with $F(T)$ being the rate function $V_{\mathrm{c}}$ or $V_{j}, k_{25}$ the maximum of each rate $\left(\mathrm{Vc}_{\max }\right.$ or $\left.\mathrm{Vj}_{\max }\right)$ at a reference temperature $T_{25}$ $\left(25^{\circ} \mathrm{C}\right.$ or $298 \mathrm{~K}$; note that $\mathrm{Vc}_{\max }$ and $\mathrm{Vj}_{\max }$ are linked by a linear function being temperature dependent), $T$ the current temperature $(\mathrm{K}), E_{\mathrm{a}}$ the activation energy, $E_{\mathrm{d}}$ the deactivation energy, $\Delta S$ the entropy factor and $R$ the ideal gas constant (Table 5).

The entropy factor $\Delta \mathrm{S}$ for $\mathrm{V} \mathrm{c}_{-} \max$ or $\mathrm{Vj}_{\_} \max$ is calculated as follows:

$\Delta \mathrm{S}=a+b \times t_{\mathrm{m}}$,

with $a$ and $b$ two constants (Table 5). This formulation from Kattge and Knorr (2007) includes an adaptation of seasonal growth temperature (derived from the spatial relation between $\mathrm{Vc}_{-} \max$ and $J_{\max }$ in TRY database and extrapolated for temporal equations). Observations by Miller and Smith (2012) of the optimal temperature for photosynthesis for graminoids and forb tundra $\left(10\right.$ to $\left.20^{\circ} \mathrm{C}\right)$ were used to define new parameter values, which were then optimised (list of variables in Table 5). The optimisation procedure is described in Sect. 2.6.1.

According to Bonan et al. (2003) and Iversen et al. (2015), the depth over which $95 \%$ of the root is located corresponds roughly to $0.5 \mathrm{~m}$ for boreal $\mathrm{C}_{3}$ grasses and to $1 \mathrm{~m}$ for temperate $\mathrm{C}_{3}$ grasses. Using this estimate we changed the a priori value of the root profile shape parameter $\left(r_{\mathrm{p}}\right.$ parameter; see Eq. 5 and de Rosnay, 1999) for cold grasses and after optimisation (see Table 5) we obtained that $95 \%$ of the roots are within the first $40 \mathrm{~cm}$ of the soil.

The specific leaf area (SLA) was also optimised for cold climate grasses, using as a priori the initial values from $\mathrm{C}_{3}$ temperate grasses. Note that we did not add any bioclimatic limits, such as (i) survival or establishment temperature thresholds as proposed by Bonan et al. (2003) and Oleson et al. (2013) or (ii) a cumulated degree-day threshold (above the zero-degree criteria) for the plant growth (Miller and Smith, 2012). In this study we use ORCHIDEE without the dynamic vegetation module, but with a prescribed vegetation cover preventing vegetation development in unfavourable areas.

\subsection{Observations and vegetation distribution}

\subsubsection{Field survey data}

The calibration of the parameters entered in the equations of NVPs, shrubs and cold climate grasses is based on observations for the period 1993-2001 gathered in Peregon et al. (2008) and extended up to 2013 for this study. The data set contains georeferenced point-scale observations of the total summertime living biomass $\left(\mathrm{g} \mathrm{m}^{-2}\right)$ and annual net primary productivity NPP $\left(\mathrm{g} \mathrm{m}^{-2} \mathrm{yr}^{-1}\right)$ for non-vascular plants (mosses and lichens) and vascular plants (grasses and shrubs) in boreal wetlands. Test sites for field observations are located in western Siberia (lat 55 to $71^{\circ} \mathrm{N}$, long 63 to $91^{\circ} \mathrm{E}$ ), which is suited for spatial analysis of NPP and biomass 
Table 5. Boreal $\mathrm{C}_{3}$ grasses parameters.

\begin{tabular}{llrr}
\hline Parameters & Description & Original $\mathrm{C}_{3}$ grass & Boreal $\mathrm{C}_{3}$ grass \\
\hline $\mathrm{Vc}_{\max (25)}\left(\mathrm{mol} \mathrm{m}^{-2} \mathrm{~s}^{-1)}\right.$ & Maximum rate of carboxylation at $25^{\circ} \mathrm{C}$ & 70 & $40^{*}$ \\
$E_{\mathrm{a}}\left(\mathrm{J} \mathrm{mol}{ }^{-1}\right)$ & Activation energy & 71513 & 71513 \\
$E_{\mathrm{d}}\left(\mathrm{J} \mathrm{mol}^{-1}\right)$ & Deactivation energy & 200000 & $200000^{*}$ \\
$a\left(\mathrm{~J} \mathrm{~mol}^{-1} \mathrm{~K}^{-1}\right)$ & Entropy constant & 668.39 & 668.39 \\
$b\left(\mathrm{~J} \mathrm{~mol}^{-1} \mathrm{~K}^{-1}{ }^{\circ} \mathrm{C}^{-1}\right)$ & Entropy constant & -1.07 & $0.0^{*}$ \\
$J_{\mathrm{max}_{(25)}}$ & Maximum rate of electron transport at $25^{\circ} \mathrm{C}$ & & 49884 \\
$E_{\mathrm{a}}\left(\mathrm{J} \mathrm{mol}^{-1}\right)$ & Activation energy & 200000 & $200000^{*}$ \\
$E_{\mathrm{d}}\left(\mathrm{J} \mathrm{mol}^{-1}\right)$ & Deactivation energy & 659.7 & 659.7 \\
$a\left(\mathrm{~J} \mathrm{~mol}^{-1} \mathrm{~K}^{-1}\right)$ & Entropy constant & $-0,75$ & $0^{*}$ \\
$b\left(\mathrm{~J} \mathrm{~mol}^{-1} \mathrm{~K}^{-1}{ }^{\circ} \mathrm{C}^{-1}\right)$ & Entropy constant & 4 & $5.6^{*}$ \\
$r_{\mathrm{p}}(-)$ & Parameter to control root profile & $2.6 \times 10^{-2}$ & $2.2 \times 10^{-2} *$ \\
$\mathrm{SLA}\left(\mathrm{m}^{2} \mathrm{gC}^{-1}\right)$ & Specific leaf area & 8.314 & 8.314 \\
$R\left(\mathrm{~J} \mathrm{~mol}^{-1} \mathrm{~K}^{-1}\right)$ & Ideal gas constant & & 4 \\
\hline
\end{tabular}

* Optimised parameter (see Sect. 2.6.1). Note that $J_{\max }$ and $\mathrm{Vc}_{\max }$ parameters, namely $E_{\mathrm{d}}$ and $b$, were linked for the optimisation.

due to its flat topography along a wide latitudinal gradient and large variety of natural ecosystems, with minor anthropogenic influence.

At each test site, detailed geobotanical descriptions were recorded and biomass sampling was conducted. Sampling was repeated two or three times during the growing season at the same test sites for several consecutive years to obtain information on interannual variability. Field studies were conducted between June and October at more than $99 \%$ of the test sites, and between July and September for $90 \%$ of them. General descriptions of in-field and laboratory methods used to estimate NPP and biomass are described in Peregon et al. (2008, 2016).

The data set takes into account all components of NPP and living biomass: above-, land-surface and below-ground fractions measured in situ at different topographical features (such as hummocks, hollows, ridges). In order to avoid the "bound" effect and use of values at the border between two vegetation classes, we chose to exclusively take into account observations where the studied vegetation represented at least $10 \%$ of the surface. Spatial differences in these microsite characteristics (i.e. hydrologic and thermal regimes, nutrient availability) strongly determine vegetation characteristics, as well as NPP and biomass, and small-scale heterogeneity induced by these microsite characteristics can be as large as the large-scale variability due to climatic gradients across the area covered by the data set. Because the small-scale variability cannot be represented in a large-scale model like ORCHIDEE, and small-scale information on microsite hydrological and topographical characteristics were not available, no perfect model-data fit can be expected, and we should rather seek for a broad model-data agreement.

The data have therefore been grouped into supersites at $0.5^{\circ}$ spatial resolution, giving 36 supersites. The 36 sites have data on mosses (comprising in total 1209 individual observa-

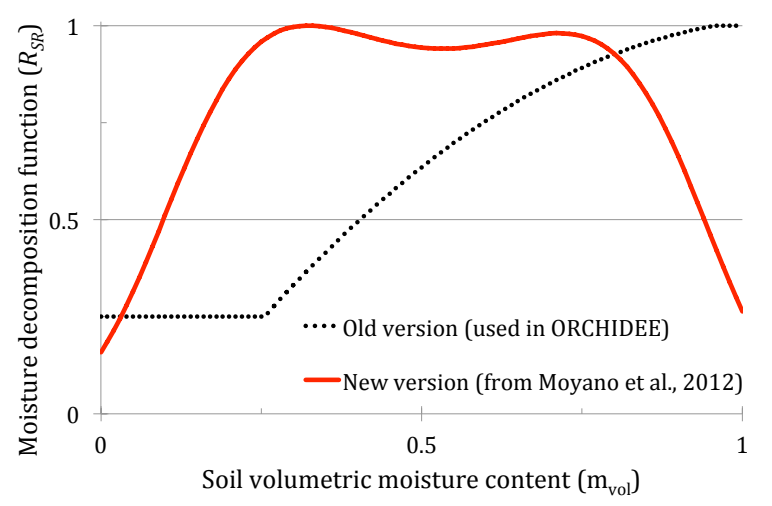

Figure 4. Moisture decomposition function used in ORCHIDEE compared to the one suggested by Moyano et al. (2012).

tions), but only 16 supersites presenting non-vascular plants, shrubs and grasses (comprising in total 660 individual observations; Fig. 5). Note, finally, that using a single data set in western Siberia (mainly lowlands) for the model calibration may introduce some biases, which will have to be evaluated.

\subsubsection{Vegetation distribution}

For this study we prescribe the spatial distribution of the vegetation, while a follow-up study will focus on the dynamics of the vegetation. We thus had to update the vegetation map used by the standard version of ORCHIDEE in order to include the spatial distribution of the new PFTs. The land cover product used to define PFT distribution in ORCHIDEE is derived from the land cover product of the European Space Agency (ESA) Climate Change Initiative (CCI; available at http://www.esa-landcover-cci.org/). The product is based on medium-resolution satellite observation and provides information on the vegetation distribution us- 


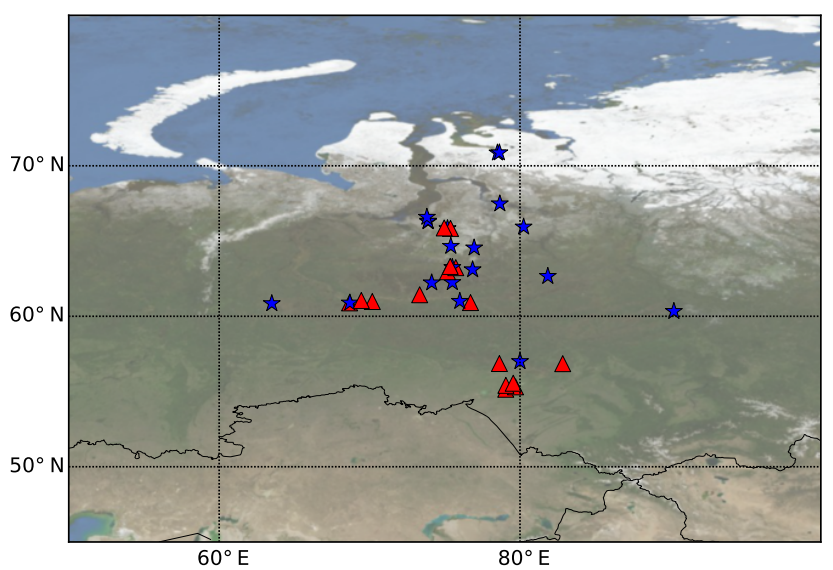

Figure 5. 36 sites of vegetation green biomass and NPP. Triangles in red: sites with NVPs, grasses and shrubs at the same location, stars in blue: sites with only NVPs.

ing land cover classes (LCC) defined by the United Nations Land Cover Classification System (UNLCCS). In order to match the satellite land cover classes with the PFTs coverage in ORCHIDEE, we use a conversion table established by Poulter et al. (2015). Note that the climate classification system of Köppen (Peel et al., 2007) is also used to further partition some vegetation types into tropical, temperate and boreal zones (see also Poulter et al., 2015). The new vegetation map is thus obtained from this Land Cover data set (version 1.6.1) transformed with a conversion table (tool available from http://maps.elie.ucl.ac.be/CCI/viewer/), from $300 \mathrm{~m} \mathrm{LCC}$ data. From the standard conversion table used in ORCHIDEE, the three new PFTs were included using the following modifications (Table S1 in the Supplement):

i. The $\mathrm{C}_{3}$ grasses (initially defined globally) that were located in class 5 of Köppen classification (polar and alpine climates) were assigned to the new cold climate $\mathrm{C}_{3}$ grasses PFT.

ii. In the original version of the conversion table, LCCs were first separated between trees and shrubs (Table S1), then aggregated into tree PFTs. Here we kept the shrubs and trees separated to define the shrub PFT coverage.

iii. "Lichens and mosses" LCC were classified by Poulter et al. (2015) into $C_{3}$ grasses and bare soil PFTs, and now are used to define a separate NVP PFT (Table S1). However, the NVP coverage that corresponds to the lichens and mosses LCC is clearly underestimated with the CCI product over Eurasia compared to North America and to other pan-Arctic land cover maps (i.e. in Circumpolar Arctic Vegetation Map, CAVM Mapping Team, 2003), in which NVP cover is much larger. In the map from Loveland et al. (2000), we noticed that the tundra biome corresponds to the "sparse vegetation" or to the "lichens and mosses" LCCs distribution. In CAVM Mapping Team (2003), the tundra biome is described as containing $\sim 30$ to $60 \%$ NVPs. Combining these two maps with the ESA CCI LCC map, we modified the conversion of "sparse vegetation" LCC in the ESA CCI map, initially to $35 \%$ bare soil and $40 \%$ grass PFTs, into $20 \%$ of bare soil, $10 \%$ cold climate grass PFT and $45 \%$ of the NVP PFT (Table S1). The remaining fraction of sparse vegetation ( $25 \%$ ) has not been modified and is considered as a mix of trees and shrubs.

The resulting spatial distribution north of $60^{\circ} \mathrm{N}$ is consistent with CAVM and Loveland et al. (2000), with 2.9, 2.2 and 2.8 million $\mathrm{km}^{2}$ NVPs, shrubs and cold climate grasses, respectively.

The distribution of the different circumboreal PFTs is presented in Fig. 6. NVPs are mainly present in northern latitudes, where climate conditions for the other PFTs are too extreme. Shrubs are present everywhere in northern latitudes but sparsely, with the tree PFTs always dominating. This is due to the approach we chose, because shrubs are diagnosed from the same LCCs as trees, with a smaller fractional coverage (Table $\mathrm{S} 1$ ). The cold climate $\mathrm{C}_{3}$ grasses come mainly from boreal forest LCCs in northern latitudes and from meadows further south (Table S1). They are dominant only in the latter.

\subsection{Optimisation strategy and evaluation protocol}

\subsubsection{Parameter optimisation strategy}

We used a Bayesian optimisation procedure to improve the value of selected parameters of the new NVPs, shrubs and boreal $\mathrm{C}_{3}$ grass PFTs. Prior information on the parameter is combined with the information that can be extracted from an ensemble of observations (see Sect. 2.5.1). Assuming that the errors associated with the parameters, the observations and the model follow Gaussian distributions, the optimal parameter set corresponds to the minimum of a cost function $J(x)$, that measures the mismatch between (i) the observations $(y)$ and the corresponding model outputs $H(x)$ (where $H$ is the model operator), and (ii) the a priori $\left(x_{b}\right)$ and optimised parameters $(x)$, weighted by their error covariance matrices (Tarantola, 1987; Eq. 21):

$$
\begin{aligned}
J(x) & =\frac{1}{2}\left[(H(x)-y)^{T} \mathbf{R}^{-1}(H(x)-y)\right. \\
& \left.+\left(x-x_{b}\right)^{T} \mathbf{B}^{-1}\left(x-x_{b}\right)\right],
\end{aligned}
$$

where $\mathbf{R}$ represents the error variance/covariance matrix associated with the observations and $\mathbf{B}$ the parameter prior error variance/covariance matrix. Note that $\mathbf{R}$ includes the errors on the measurements, model structure and the meteorological forcing. Model errors are rather difficult to assess and may be much larger than the measurement error itself. Therefore, we chose to focus on the structural error and defined the 


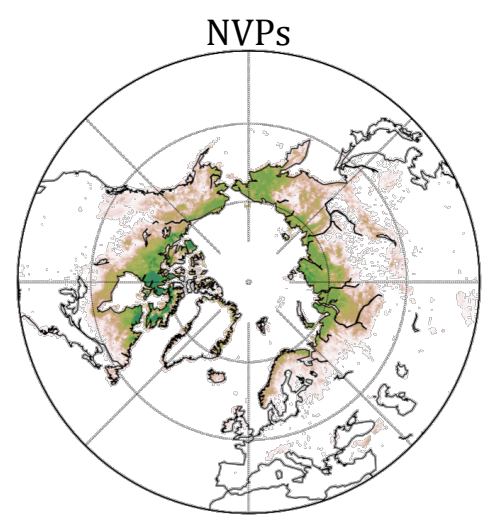

Dominance map

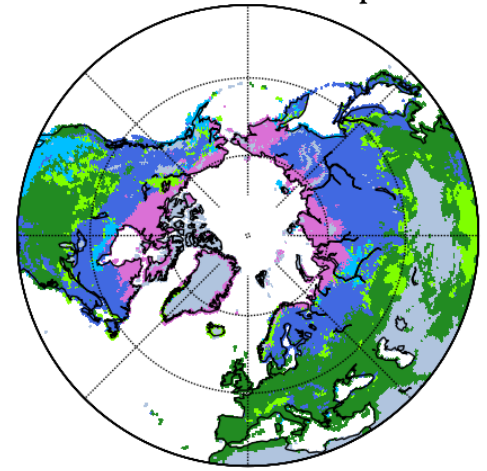

Bare soil Trees Shrubs Grasses Boreal NVPs grasses

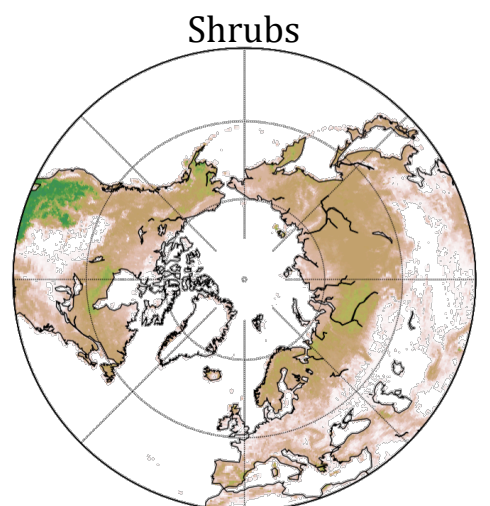

Arctic C3 grasses

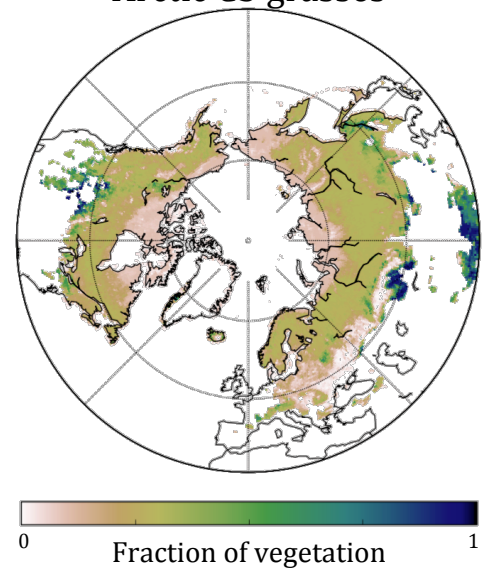

Figure 6. Map of new PFTs' vegetation coverage and dominance.

variances in $\mathbf{R}$ as the mean squared difference between the prior model and the observations (as in Kuppel et al., 2013). For simplicity we assumed that the observation error covariances were independent between the different observations and therefore we kept $\mathbf{R}$ diagonal (off-diagonal terms set to zero).

The determination of the optimal parameter vector that minimises $J(x)$ is performed using a Monte Carlo approach based on a genetic algorithm following the implementation of Santaren et al. (2014). The algorithm works iteratively, starting with a pool of vectors of parameters (i.e. the chromosomes) defined from randomly perturbed parameters. At each iteration, it randomly perturbs or exchanges parameters of the chromosomes and ranks them based on the cost function values, so that the best chromosomes (parameter combinations corresponding to the lower cost function values) produce more descendants (following the principle of natural selection). For details of the implementation see Santaren et al. (2014). Note that this algorithm is more efficient to find the minimum of $J$ than a gradient-based method as discussed in Bastrikov et al. (2018).

For each optimised parameter (Table S2), the initial values were taken from the literature or from the values used for the ORCHIDEE boreal deciduous tree PFT for shrubs and from the $\mathrm{C}_{3}$ grasses PFT for NVPs and cold climate $\mathrm{C}_{3}$ grasses. We defined the observation errors ( $\mathrm{R}$ diagonal) as $50 \mathrm{gC} \mathrm{m}^{-2}$ ( $1 \sigma$ standard deviation) for the biomass and for NPP, based on field measurement errors (Peregon et al., 2008) and a priori model data mismatch. The number of iterations was set to 25 and the number of chromosomes to 15 for NVPs and 10 for $\mathrm{C}_{3}$ grasses and shrubs, after some initial check of the convergence of the algorithm. The simulation for the optimisation was done with CRU-NCEP meteorological forcing (Wei et al., 2014; Viovy, 2015), at $0.5^{\circ}$ resolution. In order to spin up the model with respect to the living biomass, each simulation starts 10 years before the observation period for NVPs and grasses, and 19 years for shrubs.

\subsubsection{Evaluation protocol}

To illustrate the impact of new boreal vegetation compared to standard PFTs we show the results of two different simulations: one with the standard 13 PFTs of ORCHIDEE (ORC13) and the second with the new circumboreal PFTs (13 standard +3 new PFTs: ORC16). Both simulations use the CRU-NCEP meteorological forcing (Wei et al., 2014; Viovy, 2015) based on gridded monthly observations from the Climatic Research Unit (CRU) at $0.5^{\circ}$ and the climate 
re-analysis from the National Center for Environmental Prediction (NCEP) model (reduced to $2^{\circ}$ resolution), available from 1901 to 2013. We first spun up the model carbon pools (above and below ground) with a 5000-year simulation (recycling the forcing files from 1901 to 1950 randomly). We then used a transient simulation from 1901 to 2004 with linked $\mathrm{CO}_{2}$ concentration. The spatial domain is also limited to the latitudes above $40^{\circ} \mathrm{N}$.

First, the total biomass and NPP are evaluated against observations using extended data from Peregon et al. (2008). We further compare the simulated biomasses with two other Arctic transects. The first one is the North America Arctic Transect (NAAT). It is situated in a continental area, and includes eight field locations $\left(70^{\circ} \mathrm{N} 149^{\circ} \mathrm{W}\right.$ to $\left.79^{\circ} \mathrm{N} 100^{\circ} \mathrm{W}\right)$ sampled from 2002 to 2006 (Walker et al., 2011b) chosen as representative of zonal conditions. The second, located in a marine-influenced area, is the Eurasian Arctic Transect (EAT). It includes six field locations $\left(58\right.$ to $73^{\circ} \mathrm{N}$, between 67 and $81^{\circ} \mathrm{E}$ ) sampled from 2007 to 2010 (Walker et al., 2008, 2009a, b, 2011a). In order to evaluate the simulated LAI, we use the GLASS (Global Land Surface Satellite) LAI product (Liang et al., 2013; Xiao et al., 2014). This product has a temporal resolution of 8 days and is available from 1982 to 2012. Data used in this study cover the period from 2004 to 2013 and were derived from MODIS (moderate resolution imaging spectroradiometer) land surface reflectance (MOD09A1), at a resolution of $1 \mathrm{~km}$. In order to compare this GLASS product with our $2^{\circ}$ resolution simulations, an extrapolated map of the $1 \mathrm{~km}$ resolution to the $2^{\circ}$ resolution was built and a mask was applied to remove $2^{\circ}$ resolution grid cells with a land fraction below 0.7 . Finally we analyse key variables (such as NPP, albedo, soil temperature, total evaporation) to provide further insight on the impacts on carbon, energy and water fluxes. The analysis is carried out on multiple spatial and temporal scales.

Following the optimisation protocol described in Sect. 2.6.1, we calibrated 12, 6 and 7 parameters for the NVPs, shrubs and cold climate grasses respectively (see list in Tables 2, 4, 5 and S2). The optimisation relied on observations of living biomass and NPP observations presented in Sect. 2.5.1.

\section{Results}

\subsection{Model calibration and fit to the observations}

The selected observations are characterised by a very large standard deviation (SD). For cold climate grasses the SDs of the observed total biomass and NPP are close to their mean values (total biomass $=558 \pm 427$ $\mathrm{gC} \mathrm{m}^{-2} \mathrm{yr}^{-1} ; \mathrm{NPP}=321 \pm 222 \mathrm{gC} \mathrm{m}^{-2}$ ). For boreal shrubs the SDs are also very large (total biomass $=768 \pm 432$ $\mathrm{gC} \mathrm{m}^{-2} \mathrm{yr}^{-1} ; \mathrm{NPP}=321 \pm 104 \mathrm{gC} \mathrm{m}^{-2}$ ), while for NVPs they reach only half of the mean values (total biomass $=$ $\left.217 \pm 105 \mathrm{gC} \mathrm{m}^{-2} \mathrm{yr}^{-1} ; \mathrm{NPP}=117 \pm 61 \mathrm{gC} \mathrm{m}^{-2}\right)$. The cost function $(J(x)$ in Eq. 21) was reduced compared to the prior value by $31 \%$ for NVPs, $64 \%$ for shrubs and $54 \%$ for boreal $\mathrm{C}_{3}$ grasses through the optimisation (see values in Tables 2, 4,5 and $\mathrm{S} 2$ ). All results that are discussed below were obtained with the set of optimised parameters.

Scatter plots of modelled versus observed living biomass and NPP for the new PFTs and grouped by bioclimatic zones are displayed in Fig. 7. For NVPs the model mean across all sites for biomass and NPP is close to the observed mean, but the cross-site spread is not well captured. In particular the model spread is too small, especially for the forest-steppe ecosystem, indicating that the current model structure cannot simulate the spatial variability that is observed between sites. Note also that for the forest-steppe region the mean NPP and living biomass of NVPs are largely underestimated by more than 50 and $100 \mathrm{gC} \mathrm{m}^{-2}$, respectively. For cold climate $C_{3}$ grasses the model spread is much smaller than the observation spread (for both NPP and biomass), although the model mean across all sites is relatively close to the observed value. In particular the model fails to represent the large NPP and biomass for the southern ecosystem (the forest-steppe), while for the other ecosystems it overestimates the NPP and the biomass. For shrubs, the results are similar with a too low model productivity for the forest-steppe ecosystem. Overall the model captures the mean across all observations for each new PFT but shows a large bias for the southern bioclimatic region where the low simulated values are probably due to a too large water stress in the model (possibly induced by the forcing file at $2^{\circ}$ resolution in a mountainous region, unable to reproduce local conditions).

Latitudinal transects of simulated NPP and biomass over the central Siberian region are compared with observations (sites shown in Fig. 5) in Fig. 8. The simulated NPP shows broadly a maximum between 57 and $65^{\circ} \mathrm{N}$ for the three PFTs, with a decrease south of $57^{\circ} \mathrm{N}$ (by more than a factor two from 57 to $55^{\circ} \mathrm{N}$ ) and a more progressive decrease north of $65^{\circ} \mathrm{N}$. For the NVPs the northern NPP decrease occurs only after $69^{\circ} \mathrm{N}$. The observed values are broadly consistent within their uncertainties with the simulated latitudinal gradients for the selected region, although in absence of any observations north of $66^{\circ} \mathrm{N}$ for shrubs and boreal $\mathrm{C}_{3}$ grasses it is not possible to evaluate the slope of the northern decrease of the simulated productivity. For boreal $\mathrm{C}_{3}$ grasses, if we exclude two sites at 55 and $67^{\circ} \mathrm{N}$ having much larger NPP, the other sites reveal a latitudinal pattern similar to the modelled one, although with smaller values. The simulated total living biomass follows similar latitudinal patterns for the three PFTs, with higher biomass for shrubs between 57 and $65^{\circ} \mathrm{N}$ due to wood accumulation. The biomass observations for NVPs display the same pattern as in the model. For cold climate $\mathrm{C}_{3}$ grasses, without considering the two sites with very large NPP, the observed living biomass is higher than the modelled ones despite the observed lower NPP (Fig. 8 left). This is probably due to the large fraction of below- 
(a)

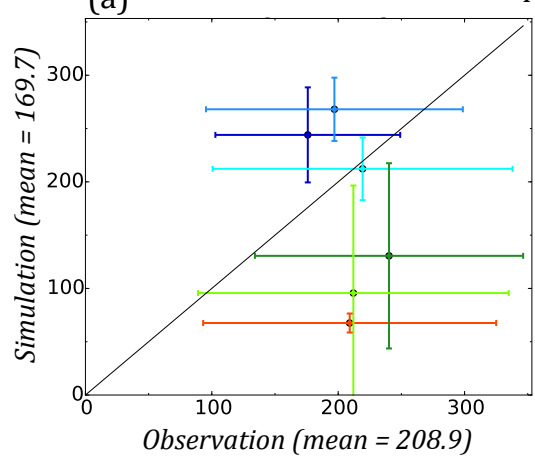

(c)

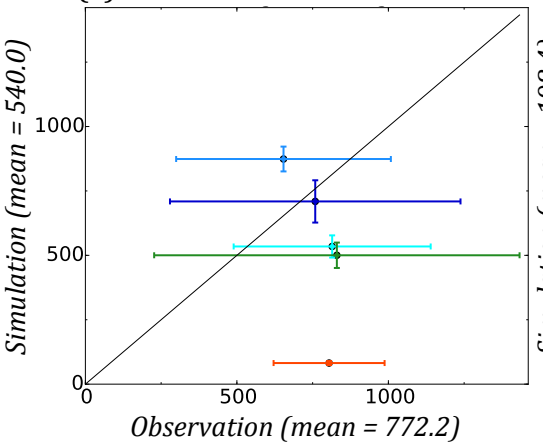

NPP $\left(g^{-} \mathrm{m}^{-2}\right)$ NVPs

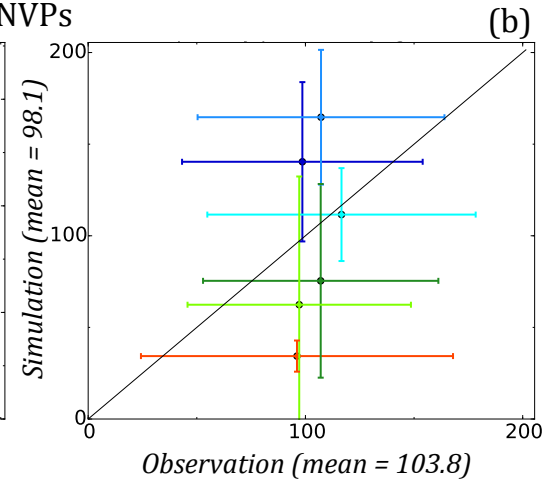

(d)

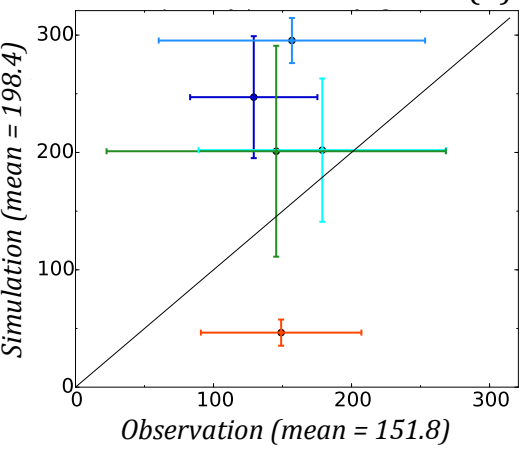

(b) (e)

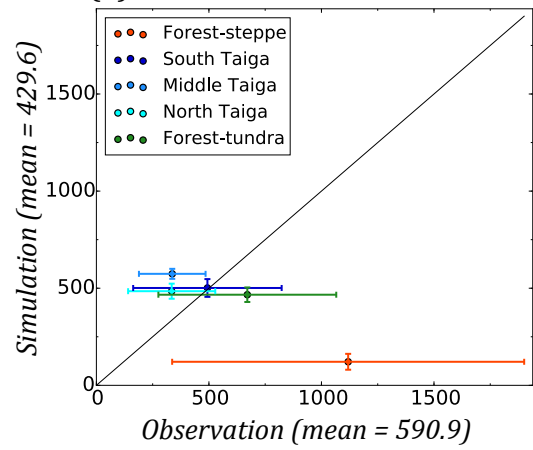

. 

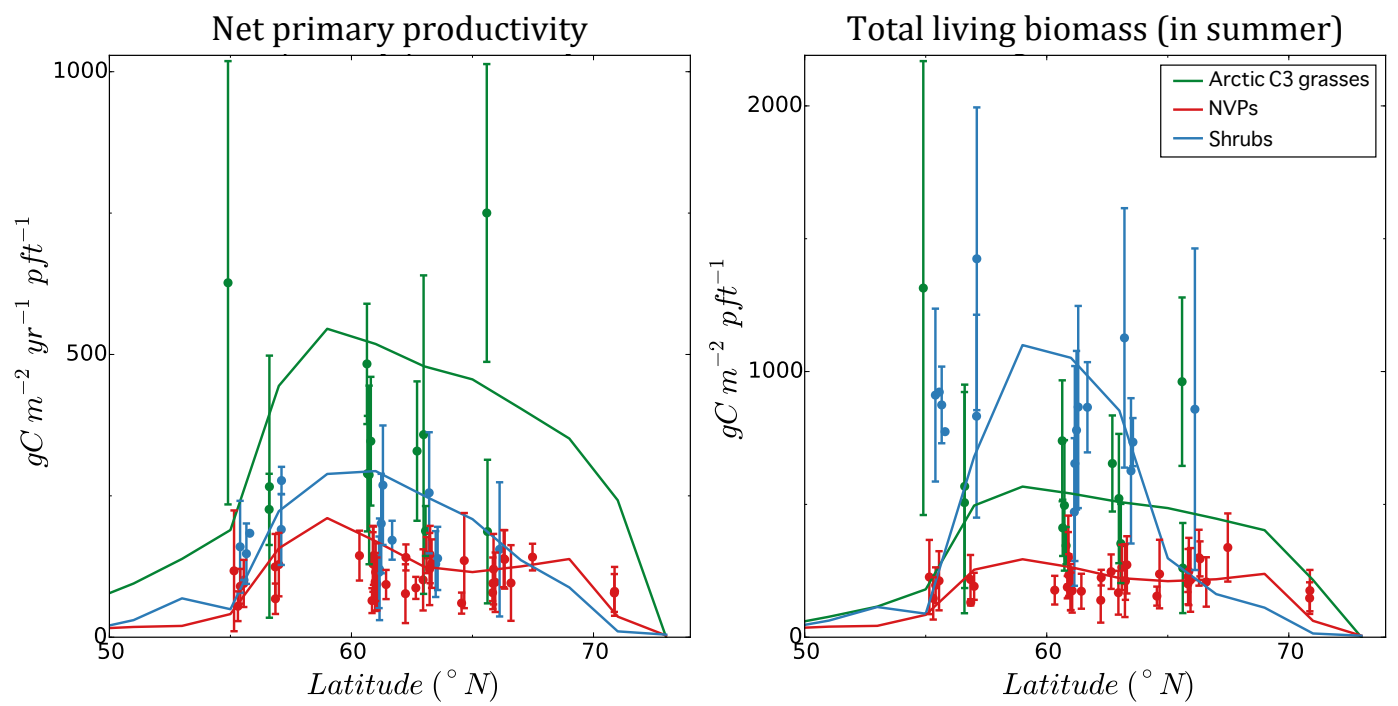

Figure 8. Latitudinal transects of the modelled and observed annual NPP and total living biomass in summer (July, August and September) over the period 2004-2013 for the new PFTs, namely boreal $\mathrm{C}_{3}$ grasses (in green), non-vascular plants (in red) and shrubs (in blue). The simulated values are averaged over the longitudinal band $78-82^{\circ} \mathrm{E}$, and per latitudinal band of $2^{\circ}$, from 50 to $74^{\circ} \mathrm{N}$. The observations are aggregated by site (averaged for all years) for each new PFT.

(a) NVPs

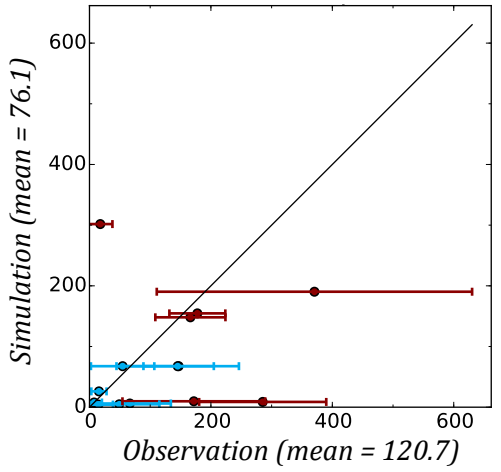

Living biomass $\left(\mathrm{gC} \mathrm{m}^{-2}\right)$

(b) Shrubs

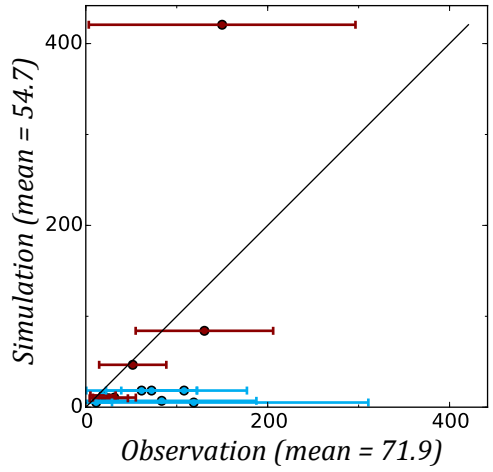

(c) Boreal C3 grasses

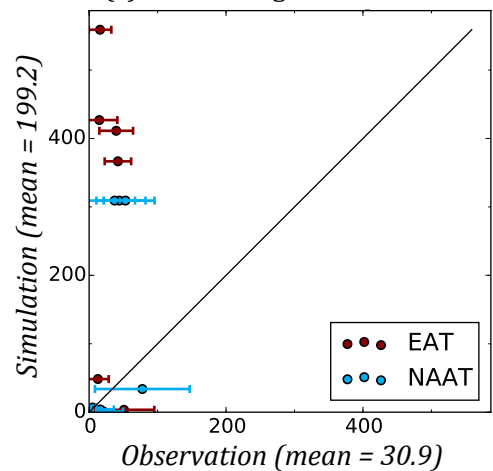

Figure 9. Model versus observed living biomass for NVPs (a), shrubs (b) and cold climate grasses (c), in two different transects: the North America Arctic Transect (in blue) and the Eurasian Arctic Transect (in red). The error bars represent the standard deviation of observations at each site.

\subsection{Evaluation of the simulated biomass and LAI}

\subsubsection{Carbon stock with two Arctic transect}

To evaluate the modelled biomass in other Arctic sites (not used in the calibration step), including uplands and lowlands, Fig. 9 shows scatter plots of observed and simulated biomass along two transects: the NAAT (North America) and the EAT (Eurasia) Arctic Transect. The NVPs and shrub biomasses are relatively well reproduced by the model (i.e. within the error bars). For both PFTs, the standard deviation of the observations includes the $1: 1$ line, but the observed biomasses are on average higher than the simulated biomasses. Simu- lated shrub biomasses are biased low for the NAAT transect but not for the EAT transect.

In contrast, the mean value of observed biomass for boreal $\mathrm{C}_{3}$ grasses (Fig. 9c) is low compared to the simulated biomasses for both cases. For half of the sites the simulated low biomass is in accordance with the observations, but for the other half the values are much larger $\left(>300 \mathrm{gC} \mathrm{m}^{2}\right.$ whereas the observation do not exceed $54 \mathrm{gC} \mathrm{m}^{2}$ ). Despite the optimisation with observations from western Siberia (Fig. 7; leading to a decrease of biomass compared to temperate $\mathrm{C}_{3}$ grasses) there is likely an overestimation of the biomass for boreal $\mathrm{C}_{3}$ grasses, probably associated with an overestimated productivity. 

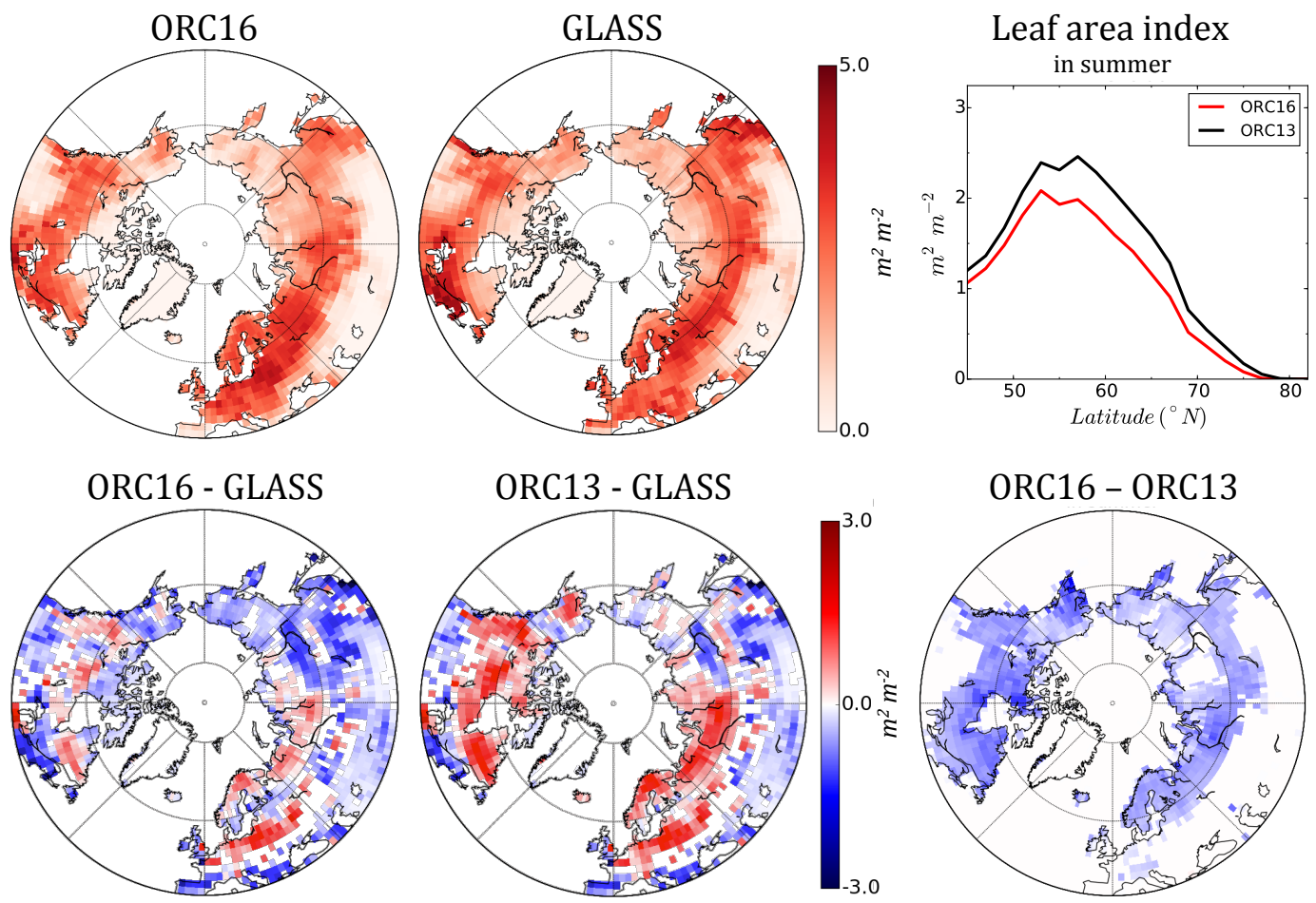

ORC16 - ORC13

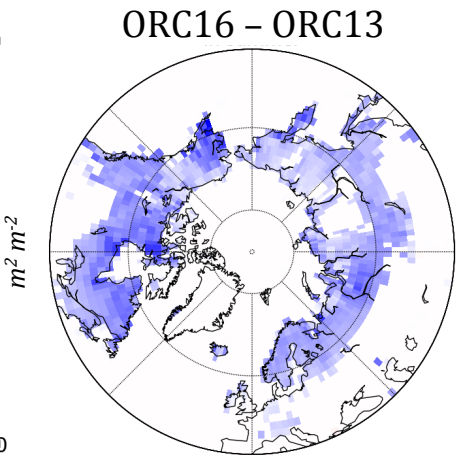

Figure 10. Global maps of LAI in summer (mean of July, August and September between 2004 and 2013) simulated by ORCHIDEE with the new PFTs (ORC16) and derived from satellite observations (GLASS LAI product, see Sect. 2.6.2), as well as the significant difference $\left(p_{\text {value }}=0.05\right)$ between the simulation with the new PFTs and the old 13 PFTs (ORC16 and ORC13 respectively), and the respective differences with the GLASS product.

\subsubsection{LAI with GLASS LAI product}

Overall, the main spatial patterns of LAI simulated with ORC16 match the patterns of the GLASS product well (Fig. 10) with (i) a latitudinal band with higher LAI around $60^{\circ} \mathrm{N}$ in Eurasia and below $60^{\circ} \mathrm{N}$ in northern America and (ii) lower LAI at low latitudes in central Siberia and in above $65^{\circ} \mathrm{N}$ in Siberia and North America. However, the model underestimates LAI in the central-west of Siberia. Comparison between GLASS product and the two model simulations (ORC16 and ORC13) indicates an overall improvement of the simulated LAI with the inclusion of the new boreal PFTs. A substantial decrease of LAI in northern Europe (from $55^{\circ} \mathrm{N}$ ), northern-western Siberia (from $55^{\circ} \mathrm{N}$ and until $135^{\circ} \mathrm{E}$ ) and northern America (from 50 $0^{\circ} \mathrm{N}$ ) is simulated in ORC16 compared to ORC13, which is in better accordance with GLASS product. This improvement with ORC16 is directly due to significantly lower LAI values in these regions (north of $55^{\circ} \mathrm{N}$ ) compared to ORC13. North of $65^{\circ} \mathrm{N}$ in Asia and America, these lower values in ORC16 are attributed to the introduction of NVPs in replacement of $\mathrm{C}_{3}$ grasses (Sect. 2.5.2) with lower LAI (see Sect. 3.3). In addition, the introduction of cold climate $\mathrm{C}_{3}$ grasses and shrubs with lower maximum LAI (e.g. 2.5 for shrubs against around 4 for tree PFTs) also contributes. Elsewhere, ORC16 and ORC13 sim- ulations present on average similar LAI anomalies compare to GLASS (mainly located in the south), except for Alaska and eastern Siberia where ORC16-GLASS anomalies are slightly more negative than with ORC13.

\subsection{Carbon fluxes and stocks of the new PFTs: spatiotemporal variations}

\subsubsection{Latitudinal gradients}

On average, a similar latitudinal gradient in terms of biomass (Fig. 11a) and productivity (Fig. 11b) for all PFTs is obtained with a maximum of biomass and productivity around $60^{\circ} \mathrm{N}$. Further north and until $80^{\circ} \mathrm{N}$, an important decrease of NPP and biomass can be observed, with an even steeper slope for shrubs. The shape of these latitudinal gradients is primarily controlled by the climate (Fig. S1 in the Supplement), in particular for precipitation and temperature gradients and with a strong influence of the topography.

On average, boreal $\mathrm{C}_{3}$ grasses have comparable living biomass but lower NPP than temperate $\mathrm{C}_{3}$ grasses in the southern latitudes where both PFTs are present. NVPs on the other hand always have a much lower productivity and living biomass than grasses (more than $50 \%$ lower). Despite the NVP implementation being based on $\mathrm{C}_{3}$ grasses, we notice that the latitudinal gradients of both productiv- 
(a) Latitudinal transects (mean 2004-2013)

(b)
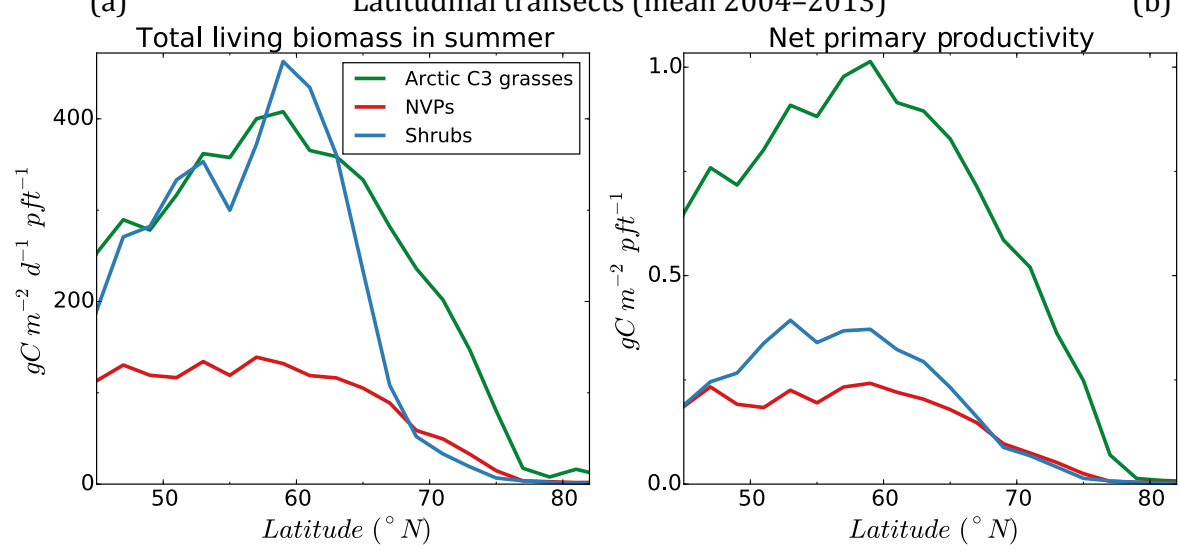

(c)

Times series (from $55^{\circ} \mathrm{N}$ )

(d)
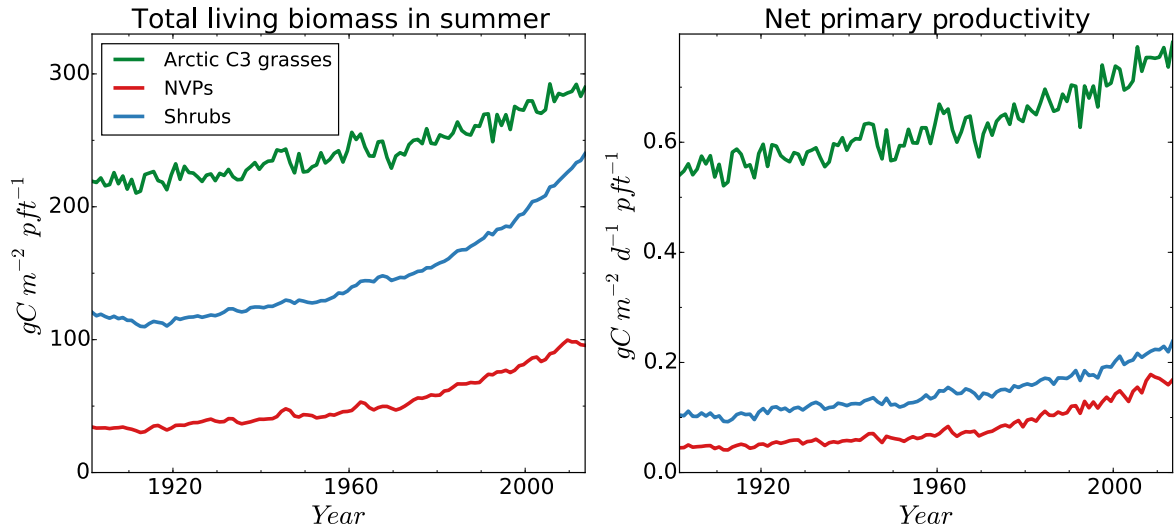

Figure 11. Latitudinal transects (mean 2004-2013, a, b) and time series (from $55^{\circ} \mathrm{N}, \mathbf{c}, \mathbf{d}$ ) of the total living biomasses (a, c) and the net primary productivity (NPP, $\mathbf{b}, \mathbf{d}$ ) of new PFTs (boreal $\mathrm{C}_{3}$ grasses in green, NVPs in red and boreal shrubs in blue), simulated in ORC16. The total living biomasses are the mean of July, August and September.

ity and living biomass differ between these two PFTs, with smoother latitudinal variations for the NVPs than the ones for boreal $\mathrm{C}_{3}$ grasses, illustrating the importance of the added processes for the NVPs (resistance to extreme conditions, see Sects. 2.2.3 and 2.2.4). Similarly, shrubs systematically display a lower NPP (by a factor of 2) and much lower biomass (factor 20, see Fig. S3) than the corresponding boreal deciduous trees, although with similar latitudinal patterns. The reduced biomass accumulation for shrubs is controlled by the new allometry relations described in Sect. 2.3.1, a lower residence time (i.e. higher mortality) and a higher fraction of GPP lost as growth respiration (Sect. 2.3.5).

These lower biomass and NPP of the new boreal PFTs compared to the PFT from which they are derived reflect a globally lower value in simulation ORC16 than in ORC13 (without the new PFT). For example, the NPP is lower by $31 \%$ north of $55^{\circ} \mathrm{N}$.

\subsubsection{Temporal evolution}

On average, the simulated productivity increases for the three regions (Figs. 11d and S2) by around $27 \%$ for boreal C3 20 grasses, $210 \%$ for NVPs and $80 \%$ for boreal shrubs (versus $35 \%$ for trees, Fig S3) from 1950 to 2013. The simulated biomass increases (Figs. 11c, S2) by the same proportion as the NPP for cold climate grasses and NVPs $(+23$ and $+200 \%$, respectively), while for shrubs the increase is stronger $(+85 \%)$. It is also of interest that the biomass increase for shrubs is much larger than for boreal broadleaf trees $(+20 \%, \mathrm{~S} 3)$.

Globally, the increase of both NPP and biomass over the last 60 years is substantial for all PFTs, but largest for nonvascular plants and shrubs (see above), which are more sensitive to climate change and $\mathrm{CO}_{2}$ increase in the model. For shrubs, climate change at high northern latitudes has a direct impact on mortality in winter (Sect. 2.3.3); an increase of the minimum temperature implies a lower mortality. Importantly, we expect that the impact of climate change in the transient simulation would be small before 1950, because the 
model spin-up was done with climate forcing randomly taken from the period 1901-1950 (Sect. 2.6.2).

The mean seasonal cycle of NPP is slightly different for NVPs (Fig. S4), for which the NPP starts earlier in spring, followed by maximum reach earlier (in June). Considering that the impact of the global increase in temperature is large in spring and autumn, the NVPs can take better advantage of it. During these two periods, more than $20 \%$ of the annual increase in NPP for NVPs occurs (Fig. 11), while there is almost no increase for other PFTs. The small NPP decrease over the summer (Fig. S4) is due to the impact of desiccation during summertime (due to an increase of the water stress, see Sect. 2.2.4) that decreases the maximum potential photosynthesis rate.

\subsection{Biophysical impacts of the new boreal vegetation description}

The annual albedo (Fig. 12) shows a significant increase (up to 0.1 ) with the new boreal PFTs (ORC16) compared to the standard version (ORC13). The higher albedo occurs primarily in winter and early spring (see January and April in Fig. 12) in northern high latitudes $\left(+3.6 \%\right.$ north of $\left.55^{\circ} \mathrm{N}\right)$, whereas there is nearly no change during summertime and early autumn. If we consider the contribution from vegetation only (i.e. the mean albedo of the fraction of the grid covered by vegetation without the effect of snow cover and without bare soil) a small decrease with the new PFTs in most regions can be observed, with the exception of northern-central Siberia. These changes are due to the LAI of the different PFTs that control the fraction of the grid effectively covered by the vegetation foliage. The higher vegetation albedo in ORC13 can be attributed to the larger values of the LAI for trees compared to shrubs and for temperate $\mathrm{C}_{3}$ grasses compared to cold climate $\mathrm{C}_{3}$ grasses. In the Siberian region, the lower vegetation albedo in ORC13 occurs in early spring, while higher values are present all year round, due to changes in LAI with NVPs. Note that changing from a $\mathrm{C}_{3}$ deciduous grassland to an evergreen PFT (i.e. the NVPs) impacts the albedo even in wintertime if the snow cover is not complete. Overall, the small changes of vegetation albedo and its dissymmetry with the changes in total albedo indicate that the substantial increase in the total albedo is linked to changes in the snow albedo and/or snow cover. The snow cover is controlled by the snow depth, the vegetation type and its roughness (see Sect. 2.3.4).

Roughness length is stable throughout the year and clearly decreases with the new vegetation types (up to $-0.5 \mathrm{~m}$ (Fig. 12), which represents a decrease of $41 \%$ from $55^{\circ} \mathrm{N}$ ), due to height differences between trees and shrubs, the height being used to compute the roughness length (Eq. 17). Conversely, the snow depth and albedo are not impacted by vegetation changes, because there is no difference between trees and shrubs concerning the snow compaction (described in Sect. 2.3.2). Given that roughness and snow depth contribute to the albedo through the fraction of snow on the vegetation (Eq. 18), the modification of winter albedo is due mostly to roughness length changes.

Transpiration is affected $\left(-33 \%\right.$ from $\left.55^{\circ} \mathrm{N}\right)$, as expected mainly during the summer period - with much lower values (up to $-150 \mathrm{~mm} \mathrm{yr}^{-1} \mathrm{~m}^{-2}$ ) in July around $60^{\circ} \mathrm{N}$ in West Eurasia and below $60^{\circ} \mathrm{N}$ in North America in the ORC16 simulation versus the ORC13 simulation. Combining this information with the vegetation map, this effect is probably due to the replacement of trees by shrubs; shrubs have a lower leaf biomass, a lower photosynthesis rate (Figs. S1 to S4), and a lower roughness (Fig. 12, inducing less turbulent flow) leading to a lower transpiration. On the other hand, the introduction of NVPs, which have a higher stomatal conductance that could lead to an increase in transpiration, does not seem to have a major impact. However, if we focus on land surfaces north of $65^{\circ} \mathrm{N}$ (representing 11.2 millions $\mathrm{km}^{2}$ ), the inclusion of the new PFTs slightly changes the components of the water budget. The inputs are identical between both simulations, and the snowfall represents $53 \%$ of the total annual precipitation. The outputs represent for ORC16 and ORC13 80.7 and $77.5 \mathrm{~mm} \mathrm{yr}^{-1} \mathrm{~m}^{-2}$ respectively for the runoff, 38.5 and $30.4 \mathrm{~mm} \mathrm{yr}^{-1} \mathrm{~m}^{-2}$ for the drainage, 198.3 and $211.2 \mathrm{~mm} \mathrm{yr}^{-1} \mathrm{~m}^{-2}$ for the evaporation, and 60.7 and $68.0 \mathrm{~mm} \mathrm{yr}^{-1} \mathrm{~m}^{-2}$ for the sublimation. There is thus a slight decrease of evaporation $(-6 \%)$ and sublimation $(-11 \%)$ with the new boreal vegetation description, compensated for by an increase of the runoff $(+4 \%)$ and drainage $(+27 \%$; Fig. S5). The lower transpiration in summer simulated by ORC16 (up to $-150 \mathrm{~mm} \mathrm{yr}^{-1} \mathrm{~m}^{-2}$, see Fig. 12) is less substantial during other seasons, and it could be partly compensated by bare soil evapotranspiration. Finally, the global water balance leads to an increase of runoff and drainage to $135 \mathrm{~km}^{3} \mathrm{yr}^{-1}(+10 \%)$ north of $65^{\circ} \mathrm{N}\left(+11 \%\right.$ with $140 \mathrm{~km}^{3} \mathrm{yr}^{-1}$ north of $\left.55^{\circ} \mathrm{N}\right)$. Compared to observations (main Arctic watershed available at http: //www.r-arcticnet.sr.unh.edu/v4.0/main.html), the river discharge simulated indicates a general underestimation in the northern high latitudes, linked to an overestimation of evaporation and sublimation (Gouttevin et al., 2012). Thus, this underestimation with ORC16 is smaller than with ORC13.

The model represents the permanently frozen soil considered as permafrost limit north of $50^{\circ} \mathrm{N}$ in North America and East Asia and north of $60^{\circ} \mathrm{N}$ elsewhere (Fig. 13.a). At its southern limit, the active layer thickness seems to increase on average and by up to $1 \mathrm{~m}$ in ORC16 compared to ORC13 (Fig. 13b). The profile at $169^{\circ} \mathrm{E} 63^{\circ} \mathrm{N}$ (Fig. 13c), selected for its high NVP coverage (40\%), shows colder soil temperatures in the ORC16 simulation $\left(-0.15^{\circ} \mathrm{C}\right.$ on average from the surface to $16 \mathrm{~m}$ ), with warmest surface (0 to $1 \mathrm{~m}$ ) temperature in winter (up to $+0.25^{\circ} \mathrm{C}$ ) and coldest surface temperature in summer (up to $-0.7^{\circ} \mathrm{C}$ ). This result indicates a lower surface conductivity, due to the insulation of the first centimetres of soil by NVPs (see Sect. 2.2.5). The $45^{\circ} \mathrm{E}$ $63^{\circ} \mathrm{N}$ profile (Fig. 13b) was selected because of large dif- 


\section{Transpiration Roughness}
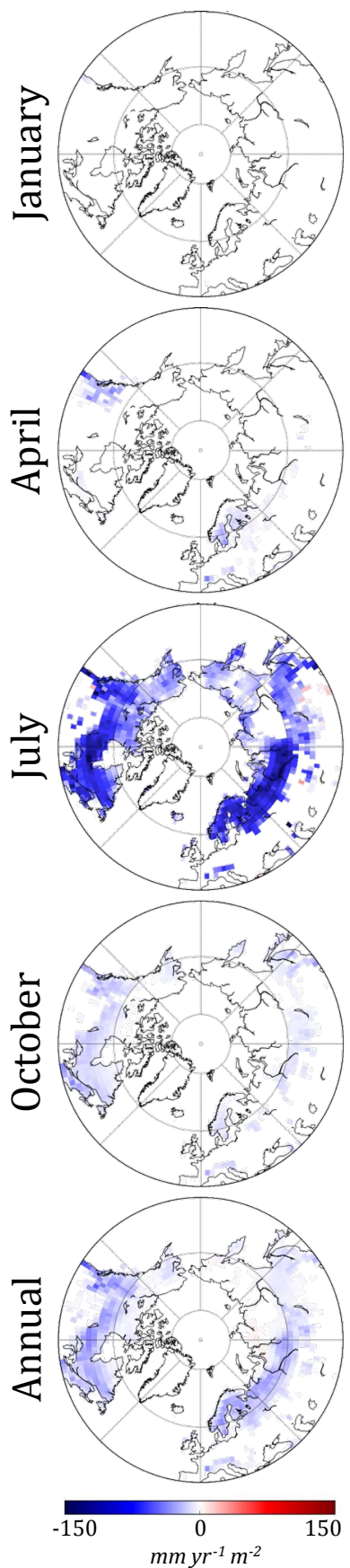

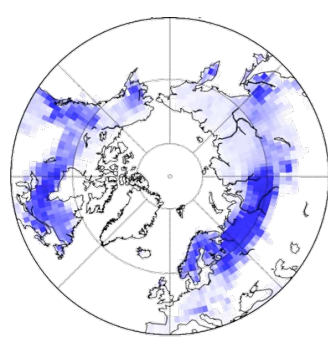

Vegetation albedo
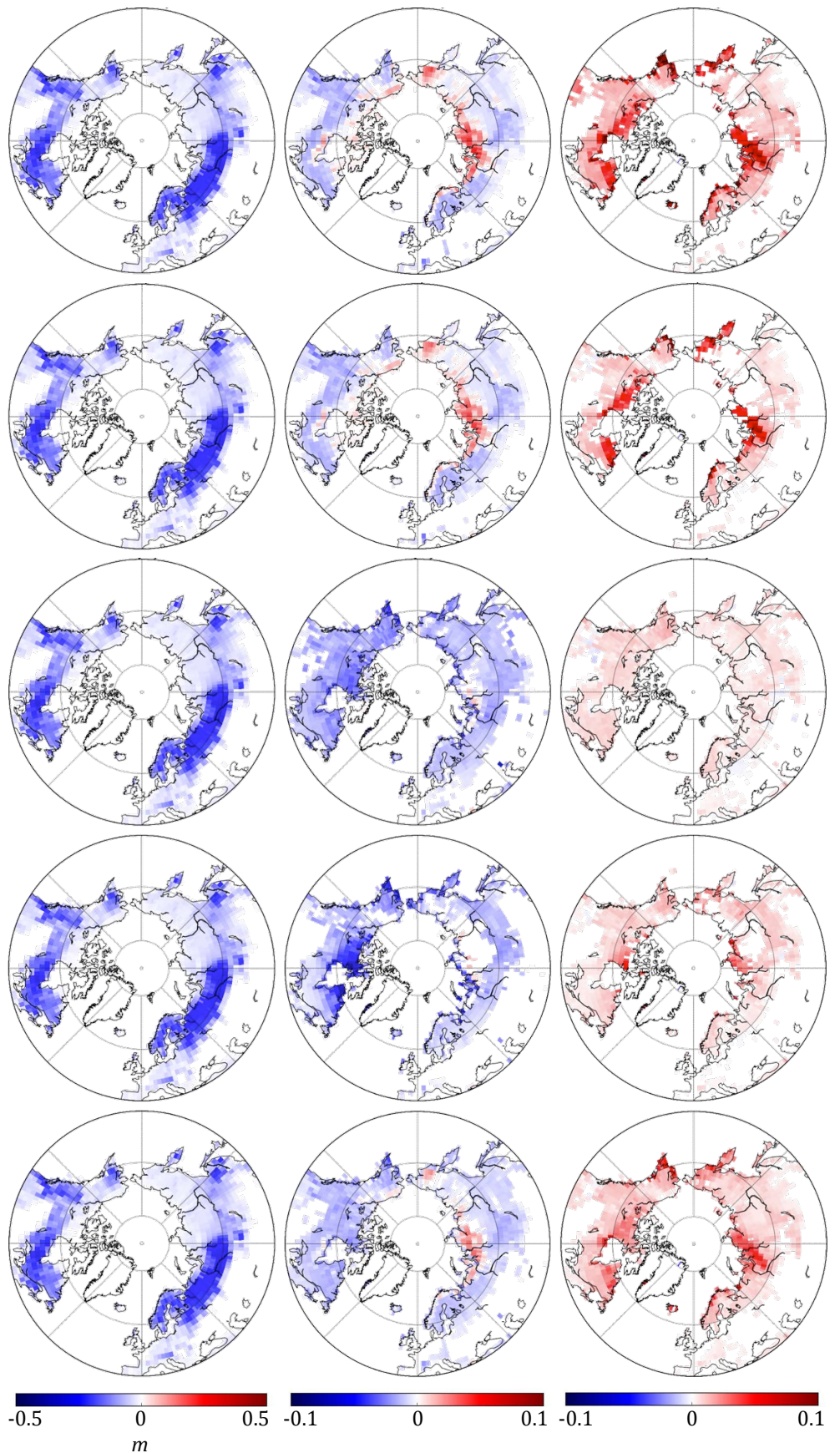

Figure 12. Maps of the significant differences $\left(p_{\text {value }}=0.05\right)$ between the simulation with 16 PFTs (ORC16 with new boreal PFTs $)$ and the simulation with 13 PFTs (ORC13 standard version), for albedo (total albedo and vegetation only without snow and bare soil contribution), roughness and transpiration for January, April, July, October, and the annual mean (mean over the period 2004 to 2013 ).

ferences between the ORC16 and ORC13 active layer thicknesses. It shows a higher soil temperature in the ORC16 simulation $\left(+0.18^{\circ} \mathrm{C}\right.$ on average, with low seasonal variation) and corresponds to a low coverage by NVPs ( $3 \%)$. This higher temperature can be explained by a large fraction of the new shrubs and cold climate $\mathrm{C}_{3}$ grasses ( $>50 \%$ ) inducing a lower transpiration (Fig. 12). The reduction of transpiration in ORC16 leads in turn to a higher soil humidity and thus a higher thermal conductivity (see $C_{\text {wet }}$ and $C_{\text {dry }}$ values in Table 2). Finally, the $65^{\circ} \mathrm{E} 61^{\circ} \mathrm{N}$ (Fig. 13b) profile was se- 
(a) Maximum thaw depth

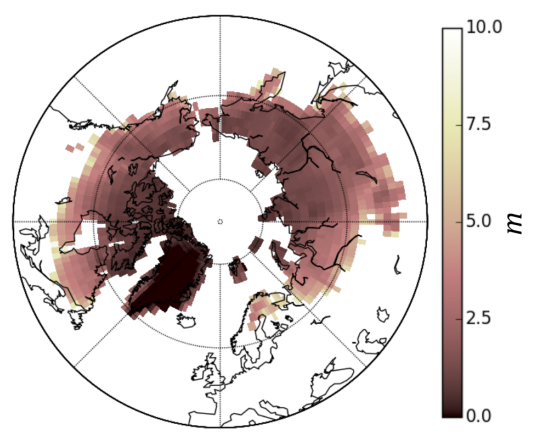

(b) Differences of thaw depth

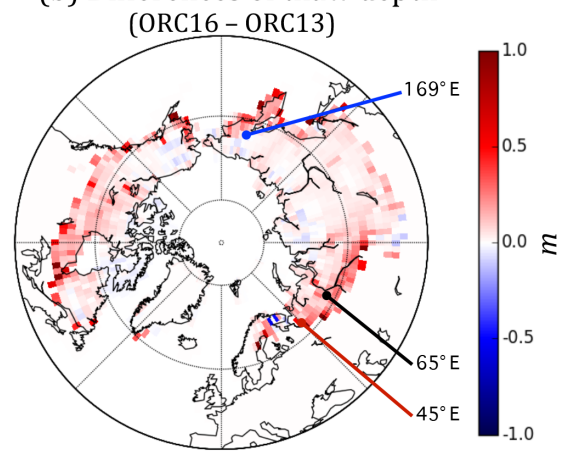

(c) Differences of soil temperature

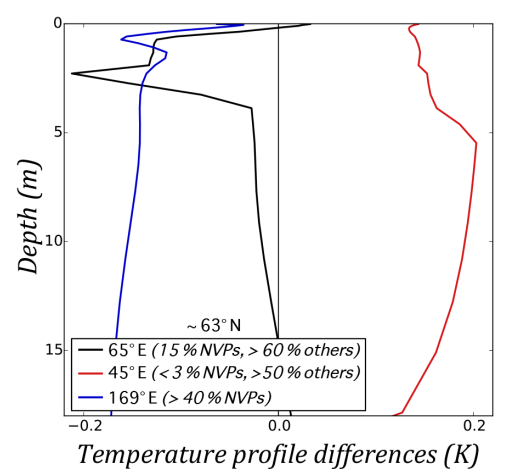

Figure 13. Map of (a) the maximum thaw depth (i.e. the active layer thickness or the maximum depth of the $0{ }^{\circ} \mathrm{C}$ isotherm) for the simulation with 16 PFTs (ORC16); (b) differences between ORC16 and the simulation with 13 PFTs (ORC13) and (c) soil temperature profile differences (mean over 2004-2013) at three selected points $\left(63^{\circ} \mathrm{N}\right.$ and $45^{\circ} \mathrm{E}, 65$ and $\left.169^{\circ} \mathrm{E}\right)$ between $\mathrm{ORC} 16$ and $\mathrm{ORC} 13$.

lected at a point where no active layer differences could be observed. It includes $75 \%$ of new boreal PFTs of which $14 \%$ are NVPs and displays colder soil temperature in ORC16 up to 5 metres (although varying with depth), but similar temperature between ORC16 and OCR13 deeper into the soil (differences below $0.05^{\circ} \mathrm{C}$ on average).

Overall, the impact of the thermal insulation by NVPs seems to be compensated by an increase of soil humidity brought about by the boreal PFTs. The active layer becomes deeper with the new boreal vascular plants (boreal $\mathrm{C}_{3}$ grasses and shrubs) due to higher soil conductivity, while the presence of NVPs decreases the active layer thickness with higher soil insulation. The coverage differences between NVPs and new vascular plant explains the global positive difference values in Fig $13 b$.

\section{Discussion}

\subsection{Challenges associated with the description of new boreal vegetation}

The implementation of a new PFT to describe non-vascular plants was challenging, as we had to introduce new or modify the standard equations and parameters to represent physiological properties of mosses and lichens. A shallow root profile was chosen to represent the access to surface water and a large leaf water and $\mathrm{CO}_{2}$ conductance was introduced to represent the lack of stomata. A specific plant resistance to water stress (through resistance to negative NPP (Sect. 2.2.3) and desiccation; Sect. 2.2.4), the impact of NVPs on soil thermal properties and a modification of litter decomposition were also implemented (Sect. 2.2). After a Bayesian parameter calibration, the simulated living biomass and productivity (Figs. 7-9) represent the observed large-scale mean gradients (i.e. between climatic zones and for transects). Furthermore, the total living biomass simulated in the 2000s (around
$100 \mathrm{gC} \mathrm{m}^{-2}$ in Fig. 11) is in accordance with the estimates given by Bond-Lamberty and Gower (2007) and Gornall et al. (2007).

For the introduction of boreal shrubs, a new allometry had to be defined (compared to trees) in order to simulate a realistic vegetation height, which is further used to describe the interactions of shrubs with snow, and in particular increased snow accumulation and density decrease near shrubs (Sect. 2.3). As for the NVPs, the simulated biomass and productivity, after the parameter optimisation, are in good agreement with the observations (Figs. 7-9). However, the snow-shrub interactions may be underestimated; Eq. (13), with a maximum snow depth obtained for a grid-cell fraction of high vegetation of 0.5 , may underestimate the impact of shrubs on snow in the case of low shrub cover. Having only few shrubs still leads to significant snow accumulation (McFadden et al., 2001; Sturm et al., 2001). Further investigation of the sub-grid scale parameterisation of snow-shrub interaction is necessary, possibly using similar equations but optimising the shrub cover fraction for which the snow depth is maximum (currently 0.5 but possibly significantly smaller).

Finally, the implementation of boreal $\mathrm{C}_{3}$ grasses is limited to parameter changes (see Table 5). However, even after calibration, the adequacy of the simulated biomass with respect to the observation remains low: in the three transects, the model largely overestimates the biomass at more than half of the sites (Figs. 7-9). Moreover, the parameter that controls the so-called entropy factor for photosynthesis rates $(b$ in Eq. 20) was optimised to zero (Tables 5 and S2), involving de facto the removal of seasonal temperature dependence of photosynthesis. This result highlights a potential limit of the Yin and Struik (2009) expression for carboxylation rate and could be due to the fact that the air temperature never gets warm enough to induce seasonal acclimation. We therefore suggest that changing only a few parameters for $\mathrm{C}_{3}$ grass is not sufficient to represent the carbon stocks and fluxes of bo- 
real grasses, and additional processes have to be considered (also possibly linked to autotrophic respiration).

Finally, note that the large data spread (Figs. 7-9) due to large spatial variability at the scale of a few metres could not be represented by the model with a $2^{\circ}$ climate forcing and there was no explicit representation of the underground vegetation (and competition) and edaphic conditions.

\subsection{Biogeochemical impacts of the new boreal vegetation}

The overall biogeochemical behaviour of the new boreal PFTs is significantly different than that of the original PFTs. NVPs exhibit a lower productivity than the cold climate $\mathrm{C}_{3}$ grasses, which is lower than the temperate $\mathrm{C}_{3}$ grasses, because of their lower maximum rate of carboxylation $\left(\mathrm{Vc}_{\max (25)}\right.$ respectively at 28, 40 and $70 \mu \mathrm{mol} \mathrm{m}^{-2} \mathrm{~s}^{-1}$ ). However, as a counterpart, the NVPs present a better adaptation to the northern latitudes, with higher productivity in spring and at the end of autumn (Fig. S4) and a decline in summer due to water stress. This behaviour corresponds to the observation that NVPs are, compared to vascular plants, most active during the shoulder seasons, due to less severe water stress and reduced competition for light (Williams and Flanagan, 1996; Campioli et al., 2009). It is thus important to include these adaptation strategies (linked to a resistance to desiccation or adapted turnover and differences in stomatal conductance and photosynthesis capacity) in global LSMs for a more accurate estimation of climate change impacts on boreal productivity. Shrubs also have a lower productivity and biomass than trees (Figs. S1-S4) because of their lower LAI, new plant allometry and adapted mortality and respiration. Of particular importance are also the differences in terms of snow protection and cold-temperature-induced mortality. These features will be crucial when dealing with dynamic vegetation rather than prescribing land cover as in this study. Overall, the inclusion of new boreal vegetation types considerably decreases the productivity, the total living biomass, and thus the LAI, which becomes closer to satellite observations (considering GLASS product, Fig. 10, Liang et al., 2013; Xiao et al., 2014; or the GIMMS product, not shown, Zhu et al., 2013). As a direct consequence, previous simulations with ORCHIDEE (and in particular those for the last IPCC, 2013 report) and possibly other models that have not explicitly described boreal NVPs, shrubs and grasses, might have significantly overestimated biomass and productivity in northern latitudes.

As expected, the simulated global increase of NPP, GPP and biomass over the last 60 years (Fig. 11) reveals the vegetation response to global warming and increased $\mathrm{CO}_{2}$. This response is substantial, especially for NVPs and boreal shrubs and particularly for the accumulation of biomass. Thus, in boreal regions the new PFTs are more sensitive to climate change than the original ones, even if their overall contribution (productivity and biomass) remains lower, im- plying that the standard ORCHIDEE version underestimates the potential changes of vegetation biomass and productivity.

\subsection{Biophysical impacts of the new boreal vegetation}

The albedo of the new boreal vegetation is still considered the same as that of the PFTs they are derived from, although the colours of these PFTs may vary substantially, with important impact on the albedo. In particular for NVPs (Porada et al., 2016), the colour may vary according to the relative humidity of the plant (Hamerlynck et al., 2000), an effect linked to the temporal dynamics of surface moisture that is difficult to capture with global models. In this study, the changes in vegetation albedo (Fig. 12) thus result directly from changes in vegetation cover. Therefore, with its lower LAI, the new boreal vegetation induces a lower soil and vegetation albedo (without taking into account the snow cover), except in winter for areas where newly introduced evergreen NVPs are present. In contrast, the overall albedo increase does not seem directly impacted by the vegetation distribution. This depends on a combination of the locally high vegetation albedo due to NVPs, and the decrease of roughness length, due to the substitution of a fraction of trees by shrubs (Sect. 2.5.2), which implies an increase of snow cover fraction (Eq. 18).

The substitution of a fraction of trees by shrubs largely contributes to the summer transpiration decrease. The active layer thickness (Fig. 13) and permafrost extent are impacted by the NVPs through two competing effects. NVPs insulate the soil as modelled in previous studies (Porada et al., 2016) but also increase the soil thermal conductivity through an increase of soil humidity due to a global decrease of transpiration. Overall, we obtain a weak or negative impact of the new boreal vegetation implementation on the permafrost extent. This is at odds with results reported elsewhere (Jorgenson et al., 2010; Soudzilovskaia et al., 2013; Chadburn et al., 2015; Porada et al., 2016). Further investigations are required to determine whether this is an artefact of our choice to replace the standard soil thermal capacity and conductivity by intermediate values between those from NVPs and mineral soil. A further improvement will be to model explicitly the energy budget of the moss layer (and heat transfer). Also note that, while the NVP heat conductivity and heat capacity used in this study are in accordance with other experiments (Soudzilovskaia et al., 2013; Chadburn et al., 2015), the average thickness of mosses in our simulation is lower than the one prescribed in Chadburn et al. (2015), where it was fixed. Moreover, NVPs have an impact on the surface soil water dynamics, not currently explicitly modelled in ORCHIDEE. For example, in JULES, Chadburn et al. (2015) chose to use a suction equation from Brooks and Corey (1964) to compute the plant water uptake and represent the "spongy" effect of NVPs. In ORCHIDEE, a first step is needed with the computation of a soil water budget for each PFT and not for the entire herbaceous layer as currently done, before we can properly represent this effect. As a direct consequence, the 
water content of surface layers may thus be underestimated, which directly impacts the soil conductivity.

Overall, the total runoff and drainage above $65^{\circ} \mathrm{N}$ with the new vegetation increases substantially with respect to the 13-PFT case (see Sect. 3.4). Future replacement of NVPs and grasses by shrubs and trees could therefore counteract the direct effect of atmospheric $\mathrm{CO}_{2}$ increase (i.e. decrease of transpiration) on Arctic river runoff (e.g. Gedney et al., 2006).

\section{Conclusions}

To improve the simulation of the energy, water and carbon budgets of boreal ecosystems with ORCHIDEE, the introduction of new PFTs was a necessary and crucial step. We have introduced the main biophysical and biochemical processes controlling NVPs and boreal shrubs functioning and applied Bayesian calibration of the most important parameters. The ability of the process-based model to simulate observed productivity and above-ground biomass has been improved by comparison to the original PFTs, likely improving the model skill to simulate carbon and water responses to climate changes. A next step will be to separate the NVPs into bryophytes and lichens, which differ with respect to their physical properties, such as water storage capacity or albedo, or their carbon fluxes (Schulze and Caldwell, 1994; Porada et al., 2016). Boreal shrubs have been reduced in this first step to broadleaf deciduous phenology, although in reality there is a mix of deciduous and evergreen broadleaf shrubs and evergreen needleleaf shrubs. It should be straightforward to split such PFT into different types, as already done for trees, with only a few varying key parameters (linked to minimum critical temperature, $\mathrm{Vc}_{\max (25)}$ or evergreen phenology type, which represents more than $48 \%$ of shrubs north of $55^{\circ} \mathrm{N}$ according to the $\mathrm{CCI}$ product and Table $\mathrm{S} 1$ ). In contrast, adapting a few selected $C_{3}$ grass parameters in order to represent boreal grasses, without including new or modifying existing processes, appears insufficient to adequately simulate the observed biomass gradient on three north-south transects.

Given the limitations discussed above, further developments are necessary to improve the model for the simulated water, carbon and energy fluxes for the Arctic region. It is important to better represent the vertical structure of the vegetation in coherence with light penetration and intra-canopy gradients of climate variables, as in Ryder et al. (2016). A more accurate vertical representation of the vegetation structure implies introducing vegetation strata with the possibility to have under-storey vegetation, such as shrubs, grasses or NVPs under a tree canopy (e.g. in Frolking et al., 1996). Furthermore, it could be important to take into account the impact of other chemical components and processes, such as the availability of oxygen in the upper soil to represent anoxic conditions and of nitrogen to account for possible limitation on plant productivity (Epstein et al., 2000; BondLamberty and Gower, 2007; Goll et al., 2012; Koven et al.,
2013). This is especially important for NVPs, which have an ecological advantage in these stressful conditions (such as poor nitrogen availability). To improve the dynamics of shrub-snow interactions, it would be important to implement an energy balance and a snow mass balance for each PFT, separately. Thereby, the interactions between wind, snow deposition and compaction and vegetation structure could be integrated (McFadden et al., 2001). In addition, shifts of vegetation are already observed (Frost and Epstein, 2014; Zhu et al., 2016) and must be taken into account in dynamical vegetation modelling. Finally, the implementation of other processes such as soil flooding (due to permafrost thawing for example) should be also considered as a crucial additional step.

The improvement of the ORCHIDEE vegetation dynamics (Krinner et al., 2005; Zhu et al., 2015) to include the new PFTs (i.e. competition between NVP, grasses, shrubs and trees) will allow the study of boreal vegetation changes, in the future and in the past, in conjunction with climate changes. The simulation of more realistic NPP and biomass in boreal landscapes could help to better simulate the dynamics of past boreal vegetation cover and boreal carbon stocks. For example, for the Last Glacial Period, it would enable a better estimation of carbon accumulation in the soil and thus of carbon stocks present in today's permafrost. Moreover, it will be possible to assess potential feedbacks between vegetation and climate with an improved description of boreal vegetation in the IPSL-CM Earth system model, of which ORCHIDEE is the surface component. For example, the simulated increase of albedo, with the new boreal PFTs and new albedo formulation (Sect. 2.3.4), could locally reduce the surface air temperature and potentially impact the snow dynamics. Moreover, the decrease of surface roughness length, due to the replacement of trees by shrubs (Sect. 2.3.1), will impact the exchange of momentum between the surface and the atmosphere and thus likely impact regional- to large-scale circulation patterns (e.g. Vautard et al., 2010).

Code availability. The code and run environment of ORCHIDEE are open source (http://forge.ipsl.jussieu.fr/orchidee). Readers interested in running the ORC-HL-VEGv1.0 version described in this paper can have access to the code (available at https://github.com/ ArseneD/ORC-HL-VEG/commit/b74ae16) and are encouraged to contact the corresponding author for full details and practicality.

\section{The Supplement related to this article is available online at https://doi.org/10.5194/gmd-10-4693-2017- supplement.}

Competing interests. The authors declare that they have no conflict of interest. 
Acknowledgements. This study was made possible thanks to the GAP Swedish-French project and PAGE21. The authors acknowledge financial support by the European Union Seventh Framework Programme (FP7/2007-2013) project PAGE21, under GA282700, as well as a French-Swedish programme that has funded the first author's $\mathrm{PhD}$, through the GAP project. We would also like to thank Deborah Verfaillie for constructive feedback and discussion and Jennifer Timm for her help in correcting the language.

Edited by: Jatin Kala

Reviewed by: three anonymous referees

\section{References}

Aiba, S.-I. and Kohyama, T.: Tree Species Stratification in Relation to Allometry and Demography in a Warm-Temperate Rain Forest, J. Ecol., 84, 207-218, https://doi.org/10.2307/2261356, 1996.

Ball, J. T., Woodrow, I. E., and Berry, J. A.: A Model Predicting Stomatal Conductance and its Contribution to the Control of Photosynthesis under Different Environmental Conditions, in: Progress in Photosynthesis Research, edited by: Biggins, J., 221-224, Springer Netherlands, Dordrecht, available at: http:// link.springer.com/10.1007/978-94-017-0519-6_48 (last access: 28 April 2016), 1987.

Bastrikov, V., MacBean, N., Peylin, P., Bacour, C., Santaren, D., and Kuppel, S.: Land surface model parameter optimisation using in-situ flux data: comparison of gradient-based versus random search algorithms, in preparation, Geosci. Model Dev., 2018.

Baudena, M., Dekker, S. C., van Bodegom, P. M., Cuesta, B., Higgins, S. I., Lehsten, V., Reick, C. H., Rietkerk, M., Scheiter, S., Yin, Z., Zavala, M. A., and Brovkin, V.: Forests, savannas, and grasslands: bridging the knowledge gap between ecology and Dynamic Global Vegetation Models, Biogeosciences, 12, 18331848, https://doi.org/10.5194/bg-12-1833-2015, 2015.

Bentley, J. R., Seegrist, D., and Blakeman, D. A.: A technique for sampling low shrub vegetation, by cromwn volume classes, Res Note PSW-RN-215 Berkeley CA US Dep. Agric. For. Serv. Pac. Southwest For. Range Exp. Stn., 12 pp., 1970.

Beringer, J., Lynch, A. H., Chapin, F. S., Mack, M., and Bonan, G. B.: The Representation of Arctic Soils in the Land Surface Model: The Importance of Mosses, J. Climate, 14, 3324-3335, https://doi.org/10.1175/15200442(2001)014<3324:TROASI>2.0.CO;2, 2001.

Best, M. J., Pryor, M., Clark, D. B., Rooney, G. G., Essery, R. L. H., Ménard, C. B., Edwards, J. M., Hendry, M. A., Porson, A., Gedney, N., Mercado, L. M., Sitch, S., Blyth, E., Boucher, O., Cox, P. M., Grimmond, C. S. B., and Harding, R. J.: The Joint UK Land Environment Simulator (JULES), model description Part 1: Energy and water fluxes, Geosci. Model Dev., 4, 677-699, https://doi.org/10.5194/gmd-4-677-2011, 2011.

Blok, D., Heijmans, M. M. P. D., Schaepman-Strub, G., van Ruijven, J., Parmentier, F. J. W., Maximov, T. C., and Berendse, F.: The Cooling Capacity of Mosses: Controls on Water and Energy Fluxes in a Siberian Tundra Site, Ecosystems, 14, 1055-1065, https://doi.org/10.1007/s10021-011-9463-5, 2011a.

Blok, D., Schaepman-Strub, G., Bartholomeus, H., Heijmans, M. M. P. D., Maximov, T. C., and Berendse, F.: The response of
Arctic vegetation to the summer climate: relation between shrub cover, NDVI, surface albedo and temperature, Environ. Res. Lett., 6, 35502, https://doi.org/10.1088/1748-9326/6/3/035502, 2011b.

Bonan, G. B.: Land-atmosphere $\mathrm{CO}_{2}$ exchange simulated by a land surface process model coupled to an atmospheric general circulation model, J. Geophys. Res., 100, 2817-2831, https://doi.org/10.1029/94JD02961, 1995.

Bonan, G. B., Levis, S., Sitch, S., Vertenstein, M., and Oleson, K. W.: A dynamic global vegetation model for use with climate models: concepts and description of simulated vegetation dynamics, Glob. Change Biol., 9, 1543-1566, https://doi.org/10.1046/j.1365-2486.2003.00681.x, 2003.

Bond-Lamberty, B. and Gower, S. T.: Estimation of stand-level leaf area for boreal bryophytes, Oecologia, 151, 584-592, https://doi.org/10.1007/s00442-006-0619-5, 2007.

Bonfils, C. J. W., Phillips, T. J., Lawrence, D. M., Cameron-Smith, P., Riley, W. J., and Subin, Z. M.: On the influence of shrub height and expansion on northern high latitude climate, Environ. Res. Lett., 7, 15503, https://doi.org/10.1088/1748-9326/7/1/015503, 2012.

Boone, A.: Description du schema de neige ISBA-ES (Explicit Snow), Note Cent. Meteo-FranceCNRM, 70, 53 pp., 2002.

Brooks, R. H. and Corey, A. T.: Hydraulic Properties of Porous Media, Colorado State University Hydrology Papers, Fort Collins, Colorado, 1964.

Campioli, M., Samson, R., Michelsen, A., Jonasson, S., Baxter, R., and Lemeur, R.: Nonvascular contribution to ecosystem NPP in a subarctic heath during early and late growing season, Plant Ecol., 202, 41-53, https://doi.org/10.1007/s11258-008-9527-6, 2009.

CAVM Mapping Team: Circumpolar Arctic vegetation, 2003.

Chadburn, S., Burke, E., Essery, R., Boike, J., Langer, M., Heikenfeld, M., Cox, P., and Friedlingstein, P.: An improved representation of physical permafrost dynamics in the JULES land-surface model, Geosci. Model Dev., 8, 1493-1508, https://doi.org/10.5194/gmd-8-1493-2015, 2015.

Chalita, S. and Le Treut, H.: The albedo of temperate and boreal forest and the Northern Hemisphere climate: a sensitivity experiment using the LMD GCM, Clim. Dynam., 10, 231-240, https://doi.org/10.1007/BF00208990, 1994.

Chapin, F. S., Mcguire, A. D., Randerson, J., Pielke, R., Baldocchi, D., Hobbie, S. E., Roulet, N., Eugster, W., Kasischke, E., Rastetter, E. B., Zimov, S. A., and Running, S. W.: Arctic and boreal ecosystems of western North America as components of the climate system, Glob. Change Biol., 6, 211-223, https://doi.org/10.1046/j.1365-2486.2000.06022.x, 2000.

Chater, C., Gray, J. E., and Beerling, D. J.: Early evolutionary acquisition of stomatal control and development gene signalling networks, Curr. Opin. Plant Biol., 16, 638-646, https://doi.org/10.1016/j.pbi.2013.06.013, 2013.

Christensen, T., Jonasson, S., Callaghan, T., and Havström, M.: On the potential $\mathrm{CO} 2$ release from tundra soils in a changing climate, Appl. Soil Ecol., 11, 127-134, https://doi.org/10.1016/S09291393(98)00146-2, 1999.

Clark, D. B., Mercado, L. M., Sitch, S., Jones, C. D., Gedney, N., Best, M. J., Pryor, M., Rooney, G. G., Essery, R. L. H., Blyth, E., Boucher, O., Harding, R. J., Huntingford, C., and Cox, P. M.: The Joint UK Land Environment Simulator (JULES), model description - Part 2: Carbon fluxes and vegetation dynamics, 
Geosci. Model Dev., 4, 701-722, https://doi.org/10.5194/gmd-4701-2011, 2011.

Clark, P. U., Dyke, A. S., Shakun, J. D., Carlson, A. E., Clark, J., Wohlfarth, B., Mitrovica, J. X., Hostetler, S. W., and McCabe, A. M.: The Last Glacial Maximum, Science, 325, 710714, https://doi.org/10.1126/science.1172873, 2009.

Colleoni, F., Krinner, G., Jakobsson, M., Peyaud, V., and Ritz, C.: Influence of regional parameters on the surface mass balance of the Eurasian ice sheet during the peak Saalian (140 kya), Global Planet. Change, 68, 132-148, https://doi.org/10.1016/j.gloplacha.2009.03.021, 2009.

de Noblet, N. I., Prentice, I. C., Joussaume, S., Texier, D., Botta, A., and Haxeltine, A.: Possible role of atmosphere-biosphere interactions in triggering the Last Glaciation, Geophys. Res. Lett., 23, 3191-3194, https://doi.org/10.1029/96GL03004, 1996.

de Rosnay, P.: Représentation de l'interaction sol-végétationatmosphère dans le Modèle de Circulation Générale du Laboratoire de Météorologie Dynamique, Physique, Université Paris 6, Paris, 1999.

de Rosnay, P., Polcher, J., Bruen, M., and Laval, K.: Impact of a physically based soil water flow and soil-plant interaction representation for modeling large-scale land surface processes: PHYSICALLY BASED SOIL HYDROLOGY IN GCM, J. Geophys. Res.-Atmos., 107, ACL 3-1-ACL 3-19, https://doi.org/10.1029/2001JD000634, 2002.

Dimitrov, D. D., Grant, R. F., Lafleur, P. M., and Humphreys, E. R.: Modeling the effects of hydrology on gross primary productivity and net ecosystem productivity at Mer Bleue bog, J. Geophys. Res., 116, G04036, https://doi.org/10.1029/2010JG001586, 2011.

Douville, H., Royer, J.-F., and Mahfouf, J.-F.: A new snow parameterization for the Météo-France climate model: Part I: validation in stand-alone experiments, Clim. Dynam., 12, 21-35, https://doi.org/10.1007/BF00208760, 1995.

Dyrness, C. T.: Control of depth to permafrost and soil temperature by the forest floor in black spruce/feathermoss communities, U.S. Dept. of Agriculture, Forest Service, Pacific Northwest Forest and Range Experiment Station, Portland, Or, available at: http://catalog.hathitrust.org/Record/007408209 (last access: 17 December 2017), 1982.

Epstein, H. E., Walker, M. D., Chapin, F. S., and Starfield, A. M.: A transient, nutrient-based model of artic plant community response to climatic warming, Ecol. Appl., 10, 824-841, https://doi.org/10.1890/10510761(2000)010[0824:ATNBMO]2.0.CO;2, 2000.

Farquhar, G. D. and Sharkey, T. D.: Stomatal Conductance and Photosynthesis, Annu. Rev. Plant Physiol., 33, 317-345, https://doi.org/10.1146/annurev.pp.33.060182.001533, 1982.

Farquhar, G. D., von Caemmerer, S., and Berry, J. A.: A biochemical model of photosynthetic $\mathrm{CO} 2$ assimilation in leaves of $\mathrm{C}_{3}$ species, Planta, 149, 78-90, https://doi.org/10.1007/BF00386231, 1980.

Frolking, S., Goulden, M. L., Wofsy, S. C., Fan, S.-M., Sutton, D. J., Munger, J. W., Bazzaz, A. M., Daube, B. C., Crill, P. M., Aber, J. D., Band, L. E., Wang, X., Savage, K., Moore, T., and Harriss, R. C.: Modelling temporal variability in the carbon balance of a spruce/moss boreal forest, Glob. Change Biol., 2, 343-366, https://doi.org/10.1111/j.1365-2486.1996.tb00086.x, 1996.
Frolking, S., Roulet, N. T., Moore, T. R., Richard, P. J. H., Lavoie, M., and Muller, S. D.: Modeling Northern Peatland Decomposition and Peat Accumulation, Ecosystems, 4, 479-498, https://doi.org/10.1007/s10021-001-0105-1, 2001.

Frost, G. V. and Epstein, H. E.: Tall shrub and tree expansion in Siberian tundra ecotones since the 1960s, Glob. Change Biol., 20, 1264-1277, https://doi.org/10.1111/gcb.12406, 2014.

Gallimore, R. G. and Kutzbach, J. E.: Role of orbitally induced changes in tundra area in the onset of glaciation, Nature, 381, 503-505, https://doi.org/10.1038/381503a0, 1996.

Gedney, N., Cox, P. M., Betts, R. A., Boucher, O., Huntingford, C., and Stott, P. A.: Detection of a direct carbon dioxide effect in continental river runoff records, Nature, 439, 835-838, https://doi.org/10.1038/nature04504, 2006.

Goll, D. S., Brovkin, V., Parida, B. R., Reick, C. H., Kattge, J., Reich, P. B., van Bodegom, P. M., and Niinemets, Ü.: Nutrient limitation reduces land carbon uptake in simulations with a model of combined carbon, nitrogen and phosphorus cycling, Biogeosciences, 9, 3547-3569, https://doi.org/10.5194/bg-9-35472012, 2012.

Gornall, J. L., Jónsdóttir, I. S., Woodin, S. J., and Van der Wal, R.: Arctic mosses govern below-ground environment and ecosystem processes, Oecologia, 153, 931-941, https://doi.org/10.1007/s00442-007-0785-0, 2007.

Gouttevin, I., Krinner, G., Ciais, P., Polcher, J., and Legout, C.: Multi-scale validation of a new soil freezing scheme for a landsurface model with physically-based hydrology, The Cryosphere, 6, 407-430, https://doi.org/10.5194/tc-6-407-2012, 2012.

Haig, D.: Filial mistletoes: the functional morphology of moss sporophytes, Ann. Bot., 111, 337-345, https://doi.org/10.1093/aob/mcs295, 2013.

Hamerlynck, E., Tuba, Z., Csintalan, Z., Nagy, Z., Henebry, G., and Goodin, D.: Diurnal variation in photochemical dynamics and surface reflectance of the desiccationtolerant moss, Tortula ruralis, Plant Ecol., 151, 55-63, https://doi.org/10.1023/A:1026594623578, 2000.

Henderson-Sellers, A., McGuffie, K., and Pitman, A. J.: The Project for Intercomparison of Land-surface Parametrization Schemes (PILPS): 1992 to 1995, Clim. Dynam., 12, 849-859, https://doi.org/10.1007/s003820050147, 1996.

Hugelius, G., Virtanen, T., Kaverin, D., Pastukhov, A., Rivkin, F., Marchenko, S., Romanovsky, V., and Kuhry, P.: Highresolution mapping of ecosystem carbon storage and potential effects of permafrost thaw in periglacial terrain, European Russian Arctic, J. Geophys. Res., 116, G03024, https://doi.org/10.1029/2010JG001606, 2011.

Hugelius, G., Strauss, J., Zubrzycki, S., Harden, J. W., Schuur, E. A. G., Ping, C.-L., Schirrmeister, L., Grosse, G., Michaelson, G. J., Koven, C. D., O’Donnell, J. A., Elberling, B., Mishra, U., Camill, P., Yu, Z., Palmtag, J., and Kuhry, P.: Estimated stocks of circumpolar permafrost carbon with quantified uncertainty ranges and identified data gaps, Biogeosciences, 11, 6573-6593, https://doi.org/10.5194/bg-11-6573-2014, 2014.

IPCC: Climate Change 2013: The Physical Science Basis, Contribution of Working Group I to the Fifth Assessment Report of the Intergovernmental Panel on Climate Change, edited by: Stocker, T. F., Qin, D., Plattner, G.-K., Tignor, M., Allen, S. K., Boschung, J., Nauels, A., Xia, Y., Bex, V., and Midgley, P. M., Cambridge 
University Press, Cambridge, United Kingdom and New York, NY, USA, 2013.

Ito, A.: A historical meta-analysis of global terrestrial net primary productivity: are estimates converging?: A historical metaanalysis of global land npp, Glob. Change Biol., 17, 3161-3175, https://doi.org/10.1111/j.1365-2486.2011.02450.x, 2011.

Iversen, C. M., Sloan, V. L., Sullivan, P. F., Euskirchen, E. S., McGuire, A. D., Norby, R. J., Walker, A. P., Warren, J. M., and Wullschleger, S. D.: The unseen iceberg: plant roots in arctic tundra, New Phytol., 205, 34-58, https://doi.org/10.1111/nph.13003, 2015.

Jorgenson, M. T., Romanovsky, V., Harden, J., Shur, Y., O’Donnell, J., Schuur, E. A. G., Kanevskiy, M., and Marchenko, S.: Resilience and vulnerability of permafrost to climate changeThis article is one of a selection of papers from The Dynamics of Change in Alaska's Boreal Forests: Resilience and Vulnerability in Response to Climate Warming, Can. J. Forest Res., 40, 1219-1236, https://doi.org/10.1139/X10-060, 2010.

Kaplan, J. O., Bigelow, N. H., Prentice, I. C., Harrison, S. P., Bartlein, P. J., Christensen, T. R., Cramer, W., Matveyeva, N. V., McGuire, A. D., Murray, D. F., Razzhivin, V. Y., Smith, B., Walker, D. A., Anderson, P. M., Andreev, A. A., Brubaker, L. B., Edwards, M. E., and Lozhkin, A. V.: Climate change and Arctic ecosystems: 2. Modeling, paleodata-model comparisons, and future projections, J. Geophys. Res., 108, 8171, https://doi.org/10.1029/2002JD002559, 2003.

Kattge, J. and Knorr, W.: Temperature acclimation in a biochemical model of photosynthesis: a reanalysis of data from 36 species, Plant Cell Environ., 30, 1176-1190, https://doi.org/10.1111/j.1365-3040.2007.01690.x, 2007.

Kirkham, M. B.: Principles of soil and plant water relations, Ann. Bot., 96, 499-500, https://doi.org/10.1093/aob/mci202, 2005.

Koven, C. D., Ringeval, B., Friedlingstein, P., Ciais, P., Cadule, P., Khvorostyanov, D., Krinner, G., and Tarnocai, C.: Permafrost carbon-climate feedbacks accelerate global warming, P. Natl. Acad. Sci. USA, 108, 14769-14774, https://doi.org/10.1073/pnas.1103910108, 2011.

Koven, C. D., Riley, W. J., Subin, Z. M., Tang, J. Y., Torn, M. S., Collins, W. D., Bonan, G. B., Lawrence, D. M., and Swenson, S. C.: The effect of vertically resolved soil biogeochemistry and alternate soil $\mathrm{C}$ and $\mathrm{N}$ models on C dynamics of CLM4, Biogeosciences, 10, 7109-7131, https://doi.org/10.5194/bg-107109-2013, 2013.

Krinner, G., Viovy, N., de Noblet-Ducoudré, N., Ogée, J., Polcher, J., Friedlingstein, P., Ciais, P., Sitch, S., and Prentice, I. C.: A dynamic global vegetation model for studies of the coupled atmosphere-biosphere system: Dvgm for coupled climate studies, Global Biogeochem. Cy., 19, GB1015, https://doi.org/10.1029/2003GB002199, 2005.

Kuppel, S., Chevallier, F., and Peylin, P.: Quantifying the model structural error in carbon cycle data assimilation systems, Geosci. Model Dev., 6, 45-55, https://doi.org/10.5194/gmd-645-2013, 2013.

Lawrence, D. M. and Slater, A. G.: A projection of severe nearsurface permafrost degradation during the 21 st century, Geophys. Res. Lett., 32, L24401, https://doi.org/10.1029/2005GL025080, 2005.

Liang, S., Zhao, X., Liu, S., Yuan, W., Cheng, X., Xiao, Z., Zhang, X., Liu, Q., Cheng, J., Tang, H., Qu, Y.,
Bo, Y., Qu, Y., Ren, H., Yu, K., and Townshend, J.: A long-term Global LAnd Surface Satellite (GLASS) data-set for environmental studies, Int. J. Digit. Earth, 6, 5-33, https://doi.org/10.1080/17538947.2013.805262, 2013.

Loranty, M. M., Berner, L. T., Goetz, S. J., Jin, Y., and Randerson, J. T.: Vegetation controls on northern high latitude snow-albedo feedback: observations and CMIP5 model simulations, Glob. Change Biol., 20, 594-606, https://doi.org/10.1111/gcb.12391, 2014.

Loveland, T. R., Reed, B. C., Brown, J. F., Ohlen, D. O., Zhu, Z., Yang, L., and Merchant, J. W.: Development of a global land cover characteristics database and IGBP DISCover from $1 \mathrm{~km}$ AVHRR data, Int. J. Remote Sens., 21, 1303-1330, https://doi.org/10.1080/014311600210191, 2000.

Lufafa, A., Diédhiou, I., Ndiaye, N. A. S., Séné, M., Kizito, F., Dick, R. P., and Noller, J. S.: Allometric relationships and peak-season community biomass stocks of native shrubs in Senegal's Peanut Basin, J. Arid Environ., 73, 260-266, https://doi.org/10.1016/j.jaridenv.2008.09.020, 2009.

Martínez, A. J. and López-Portillo, J.: Allometry of Prosopis glandulosa var. torreyana along a topographic gradient in the Chihuahuan desert, J. Veg. Sci., 14, 111-120, https://doi.org/10.1111/j.1654-1103.2003.tb02133.x, 2003.

McFadden, J. P., Liston, G. E., Sturm, M., Pielke, R. A., and Chapin, F. S.: Interactions of shrubs and snow in arctic tundra: measurements and models, IAHS Publ., 270, 317-325, 2001.

Meissner, K. J., Weaver, A. J., Matthews, H. D., and Cox, P. M.: The role of land surface dynamics in glacial inception: a study with the UVic Earth System Model, Clim. Dynam., 21, 515-537, https://doi.org/10.1007/s00382-003-0352-2, 2003.

Miller, P. A. and Smith, B.: Modelling Tundra Vegetation Response to Recent Arctic Warming, AMBIO, 41, 281-291, https://doi.org/10.1007/s13280-012-0306-1, 2012.

Moyano, F. E., Vasilyeva, N., Bouckaert, L., Cook, F., Craine, J., Curiel Yuste, J., Don, A., Epron, D., Formanek, P., Franzluebbers, A., Ilstedt, U., Kätterer, T., Orchard, V., Reichstein, M., Rey, A., Ruamps, L., Subke, J.-A., Thomsen, I. K., and Chenu, C.: The moisture response of soil heterotrophic respiration: interaction with soil properties, Biogeosciences, 9, 1173-1182, https://doi.org/10.5194/bg-9-1173-2012, 2012.

Myers-Smith, I. H., Elmendorf, S. C., Beck, P. S. A., Wilmking, M., Hallinger, M., Blok, D., Tape, K. D., Rayback, S. A., MaciasFauria, M., Forbes, B. C., Speed, J. D. M., Boulanger-Lapointe, N., Rixen, C., Lévesque, E., Schmidt, N. M., Baittinger, C., Trant, A. J., Hermanutz, L., Collier, L. S., Dawes, M. A., Lantz, T. C., Weijers, S., Jørgensen, R. H., Buchwal, A., Buras, A., Naito, A. T., Ravolainen, V., Schaepman-Strub, G., Wheeler, J. A., Wipf, S., Guay, K. C., Hik, D. S., and Vellend, M.: Climate sensitivity of shrub growth across the tundra biome, Nature Climate Change, 5, 887-891, https://doi.org/10.1038/nclimate2697, 2015.

O’Donnell, J. A., Romanovsky, V. E., Harden, J. W., and McGuire, A. D.: The Effect of Moisture Content on the Thermal Conductivity of Moss and Organic Soil Horizons From Black Spruce Ecosystems in Interior Alaska, Soil Sci., 174, 646-651, https://doi.org/10.1097/SS.0b013e3181c4a7f8, 2009.

Olefeldt, D., Goswami, S., Grosse, G., Hayes, D., Hugelius, G., Kuhry, P., McGuire, A. D., Romanovsky, V. E., Sannel, A. B. K., Schuur, E. A. G., and Turetsky, M. R.: Circumpolar distribution 
and carbon storage of thermokarst landscapes, Nat. Commun., 7, 13043, https://doi.org/10.1038/ncomms13043, 2016.

Oleson, K., Lawrence, D., Bonan, G., Drewniak, B., Huang, M., Koven, C., Levis, S., Li, F., Riley, W., Subin, Z., Swenson, S., Thornton, P., Bozbiyik, A., Fisher, R., Heald, C., Kluzek, E., Lamarque, J.-F., Lawrence, P., Leung, L., Lipscomb, W., Muszala, S., Ricciuto, D., Sacks, W., Sun, Y., Tang, J., and Yang, Z.-L.: Technical description of version 4.5 of the Community Land Model (CLM), https://doi.org/10.5065/D6RR1W7M, 2013.

Parton, W. J., Stewart, J. W. B., and Cole, C. V.: Dynamics of C, $\mathrm{N}, \mathrm{P}$ and $\mathrm{S}$ in grassland soils: a model, Biogeochemistry, 5, 109131, https://doi.org/10.1007/BF02180320, 1988.

Pearson, R. G., Phillips, S. J., Loranty, M. M., Beck, P. S. A., Damoulas, T., Knight, S. J., and Goetz, S. J.: Shifts in Arctic vegetation and associated feedbacks under climate change, Nature Climate Change, 3, 673-677, https://doi.org/10.1038/nclimate1858, 2013.

Peel, M. C., Finlayson, B. L., and McMahon, T. A.: Updated world map of the Köppen-Geiger climate classification, Hydrol. Earth Syst. Sci., 11, 1633-1644, https://doi.org/10.5194/hess-11-16332007, 2007.

Peregon, A., Maksyutov, S., Kosykh, N. P., and MironychevaTokareva, N. P.: Map-based inventory of wetland biomass and net primary production in western Siberia: Wetland biomass and npp inventories, J. Geophys. Res.-Biogeo., 113, G01007, https://doi.org/10.1029/2007JG000441, 2008.

Peregon, A., Kosykh, N. P., Mironycheva-Tokareva, N. P., Ciais, P., and Yamagata, Y.: Estimation of Biomass and Net Primary Production (NPP) in West Siberian Boreal Ecosystems: In Situ and Remote Sensing Methods, in Novel Methods for Monitoring and Managing Land and Water Resources in Siberia, edited by: Mueller, L., Sheudshen, A. K., and Eulenstein, F., 233252, Springer International Publishing, Cham., available at: http: //link.springer.com/10.1007/978-3-319-24409-9_8 (last access: 28 June 2016), 2016.

Piao, S., Nan, H., Huntingford, C., Ciais, P., Friedlingstein, P., Sitch, S., Peng, S., Ahlström, A., Canadell, J. G., Cong, N., Levis, S., Levy, P. E., Liu, L., Lomas, M. R., Mao, J., Myneni, R. B., Peylin, P., Poulter, B., Shi, X., Yin, G., Viovy, N., Wang, T., Wang, X., Zaehle, S., Zeng, N., Zeng, Z., and Chen, A.: Evidence for a weakening relationship between interannual temperature variability and northern vegetation activity, Nat. Commun., 5, 5018, https://doi.org/10.1038/ncomms6018, 2014.

Porada, P., Weber, B., Elbert, W., Pöschl, U., and Kleidon, A.: Estimating global carbon uptake by lichens and bryophytes with a process-based model, Biogeosciences, 10, 6989-7033, https://doi.org/10.5194/bg-10-6989-2013, 2013.

Porada, P., Ekici, A., and Beer, C.: Effects of bryophyte and lichen cover on permafrost soil temperature at large scale, The Cryosphere, 10, 2291-2315, https://doi.org/10.5194/tc-10-22912016, 2016.

Poulter, B., MacBean, N., Hartley, A., Khlystova, I., Arino, O., Betts, R., Bontemps, S., Boettcher, M., Brockmann, C., Defourny, P., Hagemann, S., Herold, M., Kirches, G., Lamarche, C., Lederer, D., Ottlé, C., Peters, M., and Peylin, P.: Plant functional type classification for earth system models: results from the European Space Agency's Land Cover Climate Change Initiative,
Geosci. Model Dev., 8, 2315-2328, https://doi.org/10.5194/gmd8-2315-2015, 2015.

Ruszala, E. M., Beerling, D. J., Franks, P. J., Chater, C., Casson, S. A., Gray, J. E., and Hetherington, A. M.: Land Plants Acquired Active Stomatal Control Early in Their Evolutionary History, Curr. Biol., 21, 1030-1035, https://doi.org/10.1016/j.cub.2011.04.044, 2011.

Ryder, J., Polcher, J., Peylin, P., Ottlé, C., Chen, Y., van Gorsel, E., Haverd, V., McGrath, M. J., Naudts, K., Otto, J., Valade, A., and Luyssaert, S.: A multi-layer land surface energy budget model for implicit coupling with global atmospheric simulations, Geosci. Model Dev., 9, 223-245, https://doi.org/10.5194/gmd-9223-2016, 2016.

Santaren, D., Peylin, P., Bacour, C., Ciais, P., and Longdoz, B.: Ecosystem model optimization using in situ flux observations: benefit of Monte Carlo versus variational schemes and analyses of the year-to-year model performances, Biogeosciences, 11, 7137-7158, https://doi.org/10.5194/bg-11-7137-2014, 2014.

Schulze, E.-D. and Caldwell, M. M. (Eds.): Ecophysiology of Photosynthesis, Springer Berlin Heidelberg, Berlin, Heidelberg, 1994.

Schuur, E. A. G., McGuire, A. D., Schädel, C., Grosse, G., Harden, J. W., Hayes, D. J., Hugelius, G., Koven, C. D., Kuhry, P., Lawrence, D. M., Natali, S. M., Olefeldt, D., Romanovsky, V. E., Schaefer, K., Turetsky, M. R., Treat, C. C., and Vonk, J. E.: Climate change and the permafrost carbon feedback, Nature, 520, 171-179, https://doi.org/10.1038/nature14338, 2015.

Sitch, S., Smith, B., Prentice, I. C., Arneth, A., Bondeau, A., Cramer, W., Kaplan, J. O., Levis, S., Lucht, W., Sykes, M. T., Thonicke, K., and Venevsky, S.: Evaluation of ecosystem dynamics, plant geography and terrestrial carbon cycling in the LPJ dynamic global vegetation model, Glob. Change Biol., 9, 161-185, https://doi.org/10.1046/j.1365-2486.2003.00569.x, 2003.

Smith, B., Prentice, I. C., and Sykes, M. T.: Representation of vegetation dynamics in the modelling of terrestrial ecosystems: comparing two contrasting approaches within European climate space: Vegetation dynamics in ecosystem models, Global Ecol. Biogeogr., 10, 621-637, https://doi.org/10.1046/j.1466822X.2001.t01-1-00256.x, 2001.

Soudzilovskaia, N. A., van Bodegom, P. M., and Cornelissen, J. H. C.: Dominant bryophyte control over high-latitude soil temperature fluctuations predicted by heat transfer traits, field moisture regime and laws of thermal insulation, edited by: Schweitzer, J., Funct. Ecol., 27, 1442-1454, https://doi.org/10.1111/13652435.12127, 2013.

Sturm, M., Holmgren, J., McFadden, J. P., Liston, G. E., Chapin, F. S., and Racine, C. H.: Snow-Shrub Interactions in Arctic Tundra: A Hypothesis with Climatic Implications, J. Climate, 14, 336-344, https://doi.org/10.1175/15200442(2001)014<0336:SSIIAT>2.0.CO;2, 2001.

Tarantola, A.: Inverse problem theory: methods for data fitting and model parameter estimation, Elsevier; Distributors for the United States and Canada, Elsevier Science Pub. Co, Amsterdam, New York: New York, NY, USA, 1987.

Tarnocai, C., Canadell, J. G., Schuur, E. A. G., Kuhry, P., Mazhitova, G., and Zimov, S.: Soil organic carbon pools in the northern circumpolar permafrost region: SOIL ORGANIC CARBON POOLS, Global Biogeochem. Cy., 23, GB2023, https://doi.org/10.1029/2008GB003327, 2009. 
Thackeray, C. W., Fletcher, C. G., and Derksen, C.: The influence of canopy snow parameterizations on snow albedo feedback in boreal forest regions: Boreal forest snow albedo feedback, J. Geophys. Res.-Atmos., 119, 9810-9821, https://doi.org/10.1002/2014JD021858, 2014.

van Genuchten, M. T.: A Closed-form Equation for Predicting the Hydraulic Conductivity of Unsaturated Soils1, Soil Sci. Soc. Am. J., 44, 892-898, https://doi.org/10.2136/sssaj1980.03615995004400050002x, 1980.

Vautard, R., Cattiaux, J., Yiou, P., Thépaut, J.-N., and Ciais, P.: Northern Hemisphere atmospheric stilling partly attributed to an increase in surface roughness, Nat. Geosci., 3, 756-761, https://doi.org/10.1038/ngeo979, 2010.

Vavrus, S., Ruddiman, W. F., and Kutzbach, J. E.: Climate model tests of the anthropogenic influence on greenhouse-induced climate change: the role of early human agriculture, industrialization, and vegetation feedbacks, Quaternary Sci. Rev., 27, 1410 1425, https://doi.org/10.1016/j.quascirev.2008.04.011, 2008.

Viereck, L. A., Van Cleve, K., and Dyrness, C. T.: Forest Ecosystem Distribution in the Taiga Environment, in Forest Ecosystems in the Alaskan Taiga, Vol. 57, edited by: Van Cleve, K., Chapin, F. S., Flanagan, P. W., Viereck, L. A., and Dyrness, C. T., 22-43, Springer New York, New York, NY, available at: http://link.springer.com/10.1007/978-1-4612-4902-3_3 (last access: 25 February 2016), 1986.

Vihma, T. and Savijärvi, H.: On the effective roughness length for heterogeneous terrain, Q. J. Roy. Meteor. Soc., 117, 399-407, https://doi.org/10.1002/qj.49711749808, 1991.

Viovy, N.: Forcing ORCHIDEE: 1.1 CRU-NCEP, Forching OCRCHIDEE, available at: http://forge.ipsl.jussieu.fr/orchidee/ wiki/Documentation/Forcings\#a1.1CRU-NCEP (last access: 9 June 2016), 2015.

Walker, D. A., Epstein, H. E., Leibman, M. E., Moskalenko, N. G., Kuss, J. P., Matyshak, G. V., Kaarlejarvi, E., Forbes, B. C., and Barbour, E. M.: Data Report of the 2007 Yamal Expedition to Nadym, Laborovaya, and Vaskiny Dachi, Yamal Peninsula Region, Russia, AGC Data Rep. Univ. Alsk. Fairbanks Fairbanks, available at: http://www.geobotany.uaf.edu/library/ reports/WalkerDA2008_yamal_dr080211.pdf (last access: 17 December 2017), 2008.

Walker, D. A., Epstein, H. E., Leibman, M. E., Moskalenko, N. G., Kuss, J. P., Matyshak, G. V., Kaarlejarvi, E., and Barbour, E. M.: Data Report of the 2007 and 2008 Yamal Expeditions: Nadym, Laborovaya, Vaskiny Dachi, and Kharasavey, AGC Data Rep. Univ. Alsk. Fairbanks Fairbanks, 2009a.

Walker, D. A., Orekhov, P., Frost, G. V., Matyshak, G., Epstein, H. E., Leibman, M. E., Khitun, O., Khomotov, A., Daanen, R., Gobroski, K., and Maier, H. A.: The 2009 Yamal Expedition to Ostrov Belyy and Kharp, Yamal Region, Russia, AGC Data Rep. Univ. Alsk. Fairbanks Fairbanks, 2009b.

Walker, D. A., Carlson, S., Frost, G. V., Matyshak, G. V., Leibman, M. E., Orekhov, P., Khomutov, A., Khitun, O., Zhurbenko, M., Afonina, O., and Barbour, E. M.: 2010 Expedition to Krenkel Station, Hayes Island, Franz Josef Land Russia, AGC Data Rep. Univ. Alsk. Fairbanks Fairbanks, 2011a.

Walker, D. A., Kuss, P., Epstein, H. E., Kade, A. N., Vonlanthen, C. M., Raynolds, M. K., and Daniëls, F. J. A.: Vegetation of zonal patterned-ground ecosystems along the North
America Arctic bioclimate gradient: North America Arctic patterned-ground vegetation, Appl. Veg. Sci., 14, 440-463, https://doi.org/10.1111/j.1654-109X.2011.01149.x, 2011b.

Wang, F., Cheruy, F., and Dufresne, J.-L.: The improvement of soil thermodynamics and its effects on land surface meteorology in the IPSL climate model, Geosci. Model Dev., 9, 363-381, https://doi.org/10.5194/gmd-9-363-2016, 2016.

Wang, T., Ottlé, C., Boone, A., Ciais, P., Brun, E., Morin, S., Krinner, G., Piao, S., and Peng, S.: Evaluation of an improved intermediate complexity snow scheme in the ORCHIDEE land surface model: Orchidee snow model evaluation, J. Geophys. Res.Atmos., 118, 6064-6079, https://doi.org/10.1002/jgrd.50395, 2013.

Wania, R., Ross, I., and Prentice, I. C.: Integrating peatlands and permafrost into a dynamic global vegetation model: 2 . Evaluation and sensitivity of vegetation and carbon cycle processes: peatlands and permafrost IN LPJ, 2, Global Biogeochem. Cy., 23, GB3015, https://doi.org/10.1029/2008GB003413, 2009.

Wei, Y., Liu, S., Huntzinger, D. N., Michalak, A. M., Viovy, N., Post, W. M., Schwalm, C. R., Schaefer, K., Jacobson, A. R., Lu, C., Tian, H., Ricciuto, D. M., Cook, R. B., Mao, J., and Shi, X.: The North American Carbon Program Multi-scale Synthesis and Terrestrial Model Intercomparison Project - Part 2: Environmental driver data, Geosci. Model Dev., 7, 2875-2893, https://doi.org/10.5194/gmd-7-2875-2014, 2014.

Williams, T. G. and Flanagan, L. B.: Effect of changes in water content on photosynthesis, transpiration and discrimination against 13CO2 and C18O16O in Pleurozium and Sphagnum, Oecologia, 108, 38-46, https://doi.org/10.1007/BF00333212, 1996.

Wullschleger, S. D., Epstein, H. E., Box, E. O., Euskirchen, E. S., Goswami, S., Iversen, C. M., Kattge, J., Norby, R. J., van Bodegom, P. M., and Xu, X.: Plant functional types in Earth system models: past experiences and future directions for application of dynamic vegetation models in high-latitude ecosystems, Ann. Bot., 114, 1-16, https://doi.org/10.1093/aob/mcu077, 2014.

Xiao, Z., Liang, S., Wang, J., Chen, P., Yin, X., Zhang, L., and Song, J.: Use of General Regression Neural Networks for Generating the GLASS Leaf Area Index Product From Time-Series MODIS Surface Reflectance, IEEE T. Geosci. Remote Sens., 52, 209223, https://doi.org/10.1109/TGRS.2013.2237780, 2014.

Xu, L., Myneni, R. B., Chapin III, F. S., Callaghan, T. V., Pinzon, J. E., Tucker, C. J., Zhu, Z., Bi, J., Ciais, P., Tømmervik, H., Euskirchen, E. S., Forbes, B. C., Piao, S. L., Anderson, B. T., Ganguly, S., Nemani, R. R., Goetz, S. J., Beck, P. S. A., Bunn, A. G., Cao, C., and Stroeve, J. C.: Temperature and vegetation seasonality diminishment over northern lands, Nature Climate Change, 3, 581-586, https://doi.org/10.1038/nclimate1836, 2013.

Yin, X. and Struik, P. C.: $\mathrm{C}_{3}$ and $\mathrm{C}_{4}$ photosynthesis models: An overview from the perspective of crop modelling, NJAS - Wagening, J. Life Sci., 57, 27-38, https://doi.org/10.1016/j.njas.2009.07.001, 2009.

Yoshikawa, K., Bolton, W. R., Romanovsky, V. E., Fukuda, M., and Hinzman, L. D.: Impacts of wildfire on the permafrost in the boreal forests of Interior Alaska, J. Geophys. Res., 108, 8148, https://doi.org/10.1029/2001JD000438, 2002.

Zhu, D., Peng, S. S., Ciais, P., Viovy, N., Druel, A., Kageyama, M., Krinner, G., Peylin, P., Ottlé, C., Piao, S. L., Poulter, B., Schepaschenko, D., and Shvidenko, A.: Improving the dynamics of Northern Hemisphere high-latitude vegetation in the OR- 
CHIDEE ecosystem model, Geosci. Model Dev., 8, 2263-2283, https://doi.org/10.5194/gmd-8-2263-2015, 2015.

Zhu, Z., Bi, J., Pan, Y., Ganguly, S., Anav, A., Xu, L., Samanta, A., Piao, S., Nemani, R., and Myneni, R.: Global Data Sets of Vegetation Leaf Area Index (LAI)3g and Fraction of Photosynthetically Active Radiation (FPAR)3g Derived from Global Inventory Modeling and Mapping Studies (GIMMS) Normalized Difference Vegetation Index (NDVI3g) for the Period 1981 to 2011, Remote Sens., 5, 927-948, https://doi.org/10.3390/rs5020927, 2013.
Zhu, Z., Piao, S., Myneni, R. B., Huang, M., Zeng, Z., Canadell, J. G., Ciais, P., Sitch, S., Friedlingstein, P., Arneth, A., Cao, C., Cheng, L., Kato, E., Koven, C., Li, Y., Lian, X., Liu, Y., Liu, R., Mao, J., Pan, Y., Peng, S., Peñuelas, J., Poulter, B., Pugh, T. A. M., Stocker, B. D., Viovy, N., Wang, X., Wang, Y., Xiao, Z., Yang, H., Zaehle, S., and Zeng, N.: Greening of the Earth and its drivers, Nature Climate Change, 6, 791-795, https://doi.org/10.1038/nclimate3004, 2016. 